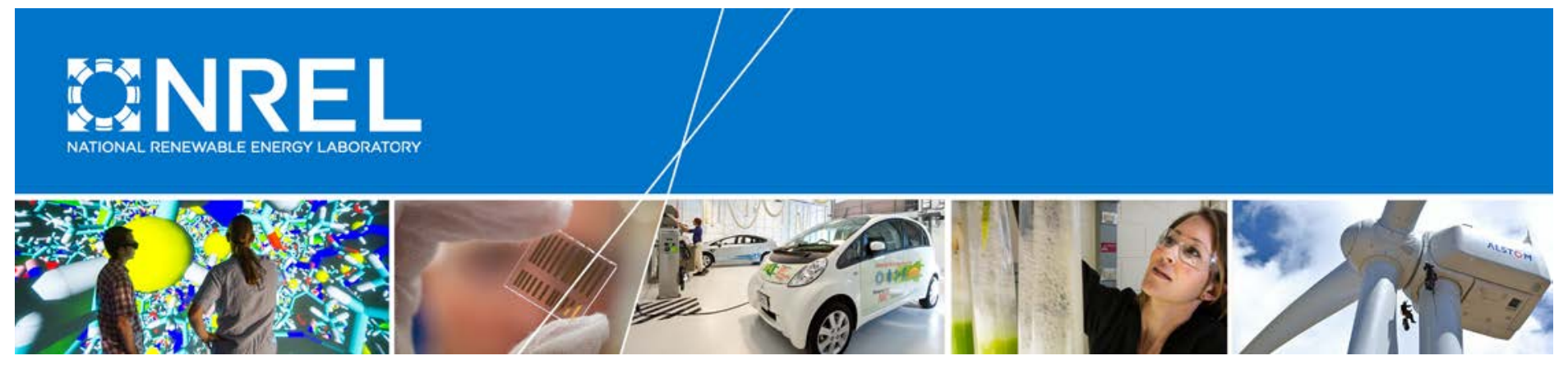

\title{
Gearbox Reliability \\ Collaborative Investigation of High-Speed-Shaft Bearing Loads
}

Jonathan Keller and Yi Guo

National Renewable Energy Laboratory

NREL is a national laboratory of the U.S. Department of Energy Office of Energy Efficiency \& Renewable Energy Operated by the Alliance for Sustainable Energy, LLC

This report is available at no cost from the National Renewable Energy Laboratory (NREL) at www.nrel.gov/publications.

Technical Report

NREL/TP-5000-66175

June 2016

Contract No. DE-AC36-08G028308 


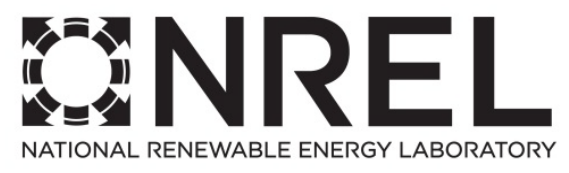

\section{Gearbox Reliability Collaborative Investigation of High-Speed-Shaft Bearing Loads}

Jonathan Keller and Yi Guo

National Renewable Energy Laboratory

Prepared under Task No. WE16.5A01

NREL is a national laboratory of the U.S. Department of Energy Office of Energy Efficiency \& Renewable Energy Operated by the Alliance for Sustainable Energy, LLC

This report is available at no cost from the National Renewable Energy Laboratory (NREL) at www.nrel.gov/publications.

National Renewable Energy Laboratory 15013 Denver West Parkway Golden, CO 80401 303-275-3000 • www.nrel.gov
Technical Report

NREL/TP-5000-66175

June 2016

Contract No. DE-AC36-08G028308 


\section{NOTICE}

This report was prepared as an account of work sponsored by an agency of the United States government. Neither the United States government nor any agency thereof, nor any of their employees, makes any warranty, express or implied, or assumes any legal liability or responsibility for the accuracy, completeness, or usefulness of any information, apparatus, product, or process disclosed, or represents that its use would not infringe privately owned rights. Reference herein to any specific commercial product, process, or service by trade name, trademark, manufacturer, or otherwise does not necessarily constitute or imply its endorsement, recommendation, or favoring by the United States government or any agency thereof. The views and opinions of authors expressed herein do not necessarily state or reflect those of the United States government or any agency thereof.

This report is available at no cost from the National Renewable Energy Laboratory (NREL) at www.nrel.gov/publications.

Available electronically at SciTech Connect http:/www.osti.gov/scitech

Available for a processing fee to U.S. Department of Energy and its contractors, in paper, from:

U.S. Department of Energy

Office of Scientific and Technical Information

P.O. Box 62

Oak Ridge, TN 37831-0062

OSTI http://www.osti.gov

Phone: 865.576.8401

Fax: 865.576.5728

Email: reports@osti.gov

Available for sale to the public, in paper, from:

U.S. Department of Commerce

National Technical Information Service

5301 Shawnee Road

Alexandria, VA 22312

NTIS http://www.ntis.gov

Phone: 800.553 .6847 or 703.605 .6000

Fax: 703.605.6900

Email: orders@ntis.gov 


\section{Acknowledgments}

This work was supported by the U.S. Department of Energy under Contract No. DE-AC3608GO28308 with the National Renewable Energy Laboratory. Funding for the work was provided by the DOE Office of Energy Efficiency and Renewable Energy, Wind and Water Power Technologies Office. 


\section{List of Acronyms}

$\begin{array}{ll}\text { CRB } & \text { cylindrical roller bearing } \\ \text { GB } & \text { gearbox } \\ \text { GRC } & \text { Gearbox Reliability Collaborative } \\ \text { HSS } & \text { high-speed shaft } \\ \text { Hz } & \text { hertz } \\ \text { kN } & \text { kilonewton } \\ \text { kNm } & \text { kilonewton-meter } \\ \text { kW } & \text { kilowatt } \\ \text { m } & \text { meter } \\ \text { mm } & \text { millimeter } \\ \text { NREL } & \text { National Renewable Energy Laboratory } \\ \text { NWTC } & \text { National Wind Technology Center } \\ \text { RPM } & \text { revolutions per minute } \\ \text { STD } & \text { standard deviation } \\ \text { TRB } & \text { tapered roller bearing } \\ & \end{array}$




\section{Nomenclature}

$D_{b}, R_{b} \quad$ Diameter and radius of the gear base circle

$F_{x, y, z}^{B P} \quad$ Forces induced by the locating bearing pair

$F_{y, z}^{C B} \quad$ Forces induced by the cylindrical bearing

$F_{x, y, z}^{D W} \quad$ Forces induced by the downwind bearing

$F_{y, z}^{U W} \quad$ Forces induced by the upwind bearing

$F^{m} \quad$ Total gear mesh force

$F_{r, x, y, z}^{m} \quad$ Gear mesh forces in the radial and $x, y$, and $z$ directions

$L \quad$ Length of high-speed shaft

$L_{A, B, C} \quad$ Axial location of measurement locations A, B, and C

$L_{C B, D W, S P, U W} \quad$ Axial point of action of support bearings

$M_{y, z}^{B P} \quad$ Moments induced by the locating bearing pair

$M_{y, z}^{A, B, C} \quad$ Moments at measurement locations A, B, and C

$M_{y, z}^{g} \quad$ Moments induced by generator coupling

T Shaft torque

$W^{d} \quad$ Weight of brake disk

$x, y, z \quad$ Gearbox coordinate system

$\alpha \quad$ Gear pressure angle

$\beta, \phi \quad$ Gear helix angle and direction

$\gamma \quad$ Gear line of action angle 


\section{Table of Contents}

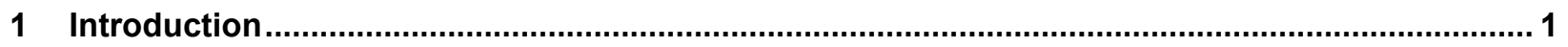

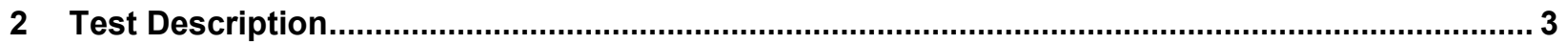

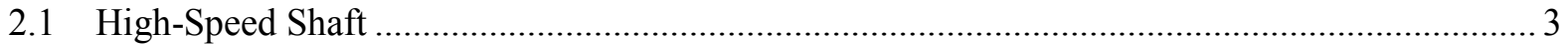

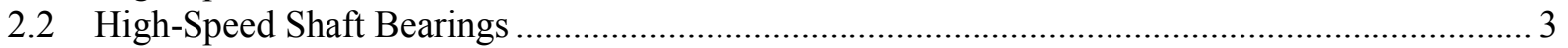

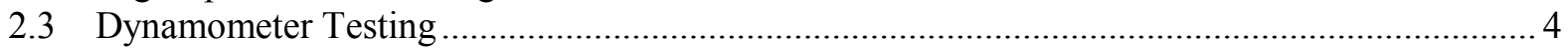

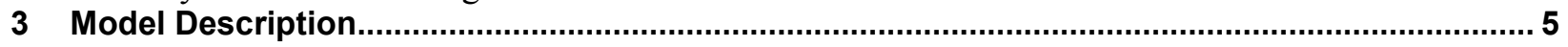

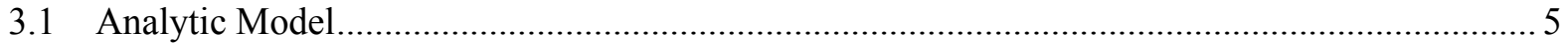

3.1.1 Locating Bearing Pair Modeled as a Single Element.................................................. 5

3.1.2 Locating Bearing Pair Modeled as Individual Elements............................................. 7

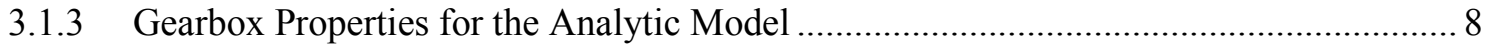

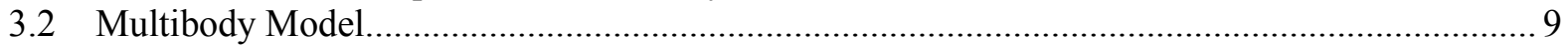

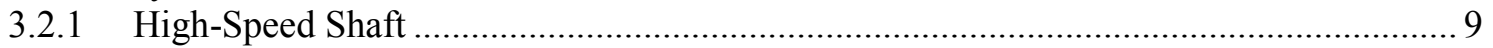

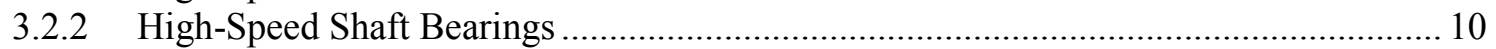

3.2.3 High-Speed Shaft Torque and Bending Moments .................................................... 10

3.3 Finite-Element/Contact Mechanics Model................................................................................ 11

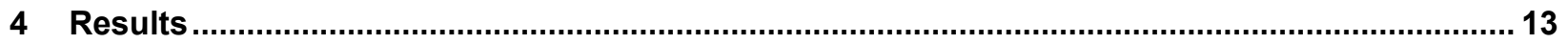

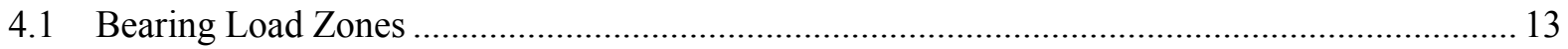

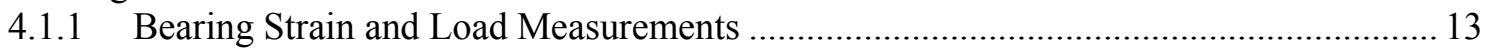

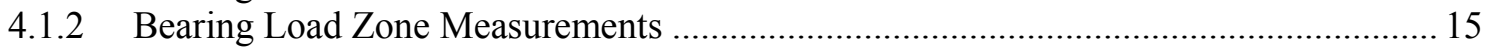

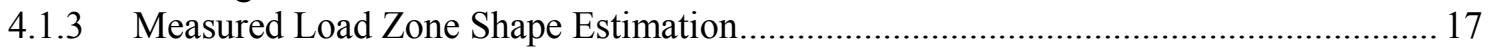

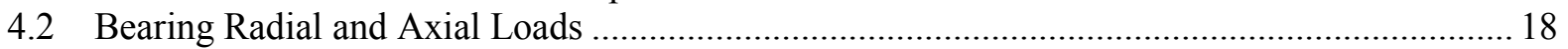

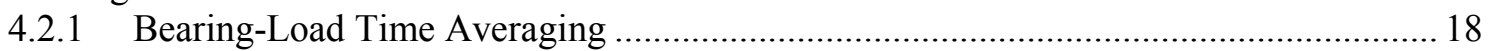

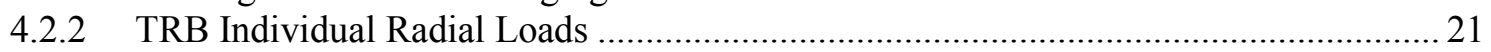

4.2.3 TRB Pair Axial Load......................................................................... 21

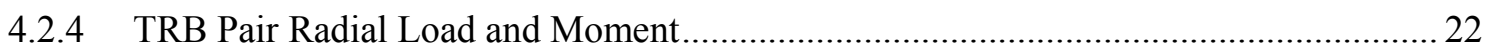

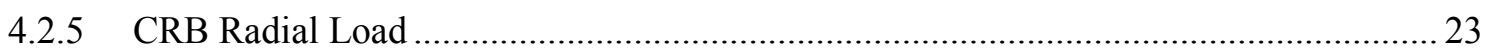

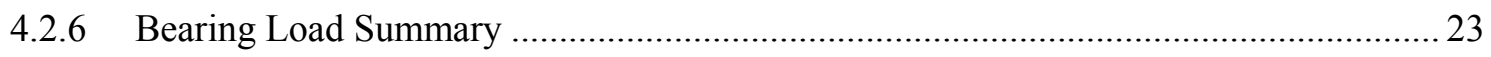

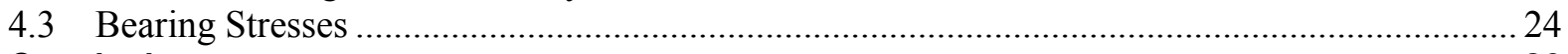

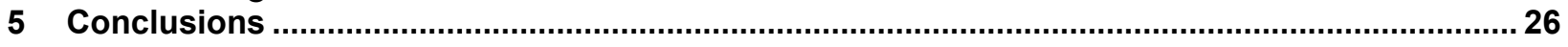

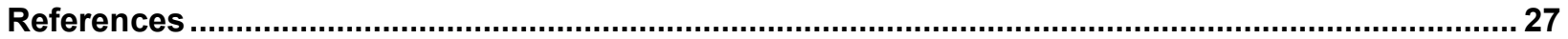




\section{List of Figures}

Figure 1. Instrumented high-speed shaft. Photo by Jonathan Keller, NREL 27895 ................................. 3

Figure 2. Downwind tapered roller bearing instrumentation. Photo by Jonathan Keller, NREL 37697 ...... 4

Figure 3. HSS free-body diagram for locating bearing pair modeled as a single element.......................... 6

Figure 4. HSS free-body diagram for locating bearing pair modeled as individual elements ..................... 7

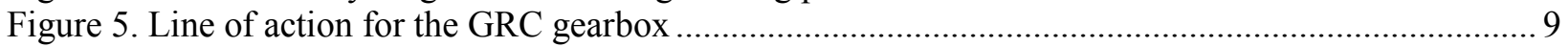

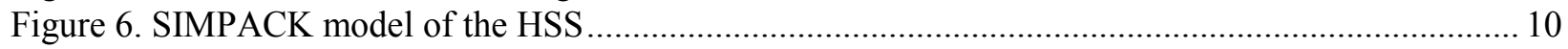

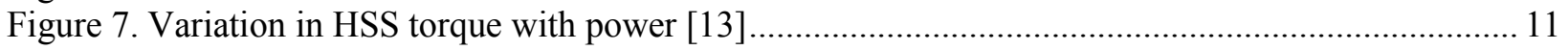

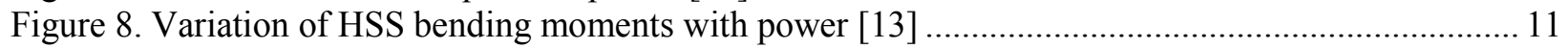

Figure 9. Transmission3D finite-element model of the high-speed shaft .............................................. 12

Figure 10. Example downwind (left) and upwind (right) TRB strain gauge measurements .................... 13

Figure 11. Example downwind (left) and upwind (right) TRB strain range measurements ...................... 14

Figure 12. Example downwind (left) and upwind (right) TRB load measurements................................ 14

Figure 13. Downwind (left) and upwind (right) TRB load zones in offline conditions .......................... 15

Figure 14. Downwind (left) and upwind (right) TRB load zones at 50\% power.................................... 16

Figure 15. Downwind (left) and upwind (right) TRB load zones at 100\% power................................... 16

Figure 16. Realistic downwind (left) and upwind (right) TRB load-zone estimates ................................ 17

Figure 17. Unrealistic downwind (left) and upwind (right) TRB load-zone estimates............................ 18

Figure 18. Processed downwind (left) and upwind (right) TRB radial loads ........................................ 19

Figure 19. Standard deviation (STD) of downwind (left) and upwind (right) TRB radial loads............... 20

Figure 20. Time-averaged downwind (left) and upwind (right) TRB radial loads .................................. 20

Figure 21. Comparison of downwind (left) and upwind (right) TRB radial loads ................................ 21

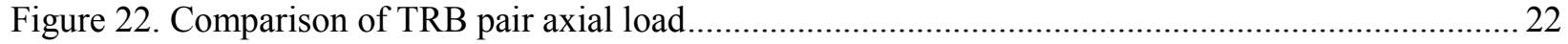

Figure 23. Comparison of TRB pair radial load (left) and moment (right) ............................................ 22

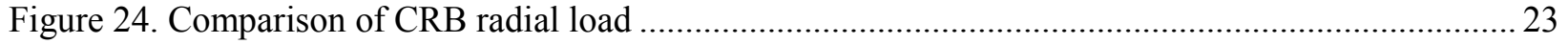

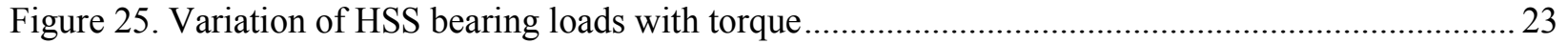

Figure 26. Downwind (left) and upwind (right) surface contact pressures............................................. 24

Figure 27. Downwind (left) and upwind (right) maximum subsurface von Mises stresses......................25

Figure 28. Downwind (left) and upwind (right) maximum subsurface shear stresses............................. 25

\section{List of Tables}

Table 1. Modeled Stiffnesses of HSS Bearings ..... 10 


\section{Introduction}

Efforts continue to improve wind turbine gearbox reliability across the industry. The most common failed components in wind turbine gearboxes are the rolling element bearings, particularly in the intermediate and high-speed stages [1]. The high failure rate and costs to repair are a large reliability concern for the industry. The most common bearing failure modes include micropitting, scuffing, and white-etching area cracks, not rolling contact fatigue [2]. White-etching area cracks are a mode of damage that can lead to a failure at $1 \%-20 \%$ of the predicted $L_{10}$ bearing design life for conventional rolling contact fatigue [3-5]. There are several theories about the cause of white-etching area cracks, including hydrogen-induced embrittlement from lubricant decomposition, high stress and slip conditions, mechanical impact loading, and multiple influencing factors without one root cause. There is general agreement in the industry that operational conditions prevalent in wind turbines, such as unsteady wind and gusts, braking, generator misalignment, and grid faults, will lead to disturbed bearing kinematics, loading, and lubrication [6]. When rollers enter and leave the shifting load zone during such events, they are prone to sliding, which can lead to surface distress and damage.

Since 2007, the National Renewable Energy Laboratory (NREL) Gearbox Reliability Collaborative (GRC) has investigated gearbox motions, loads, and deflections through the modeling, analyzing, and testing of two 750-kilowatt $(\mathrm{kW})$ gearboxes. Early efforts in Phase 1 and Phase 2 focused on planetary bearing and gear responses [7]. Currently, Phase 3 is focused on investigating loads experienced by the high-speed shaft (HSS), pinion, and supporting bearings due to the prevalence of similar failures in industry gearboxes [8]. To facilitate this, instrumentation was added and calibrated to measure the HSS bending and torque [9], pinion tooth load distribution, and radial load distribution and temperature of the locating bearings [10]. Tests were conducted in late 2014 to study the impact of nontorque loads, generator misalignment, and transient field representative conditions [11] on these loads. The primary purpose of these efforts was to compare and, ideally, validate the standard assumptions and practices utilized in simple analytic and commercial modeling tools to measured data. In doing so, the tools can then be used with confidence by industry to investigate reliability issues on specific commercial gearboxes. A secondary purpose was to investigate operations, such as transient and braking events, that are likely to lead to the disturbed bearing kinematics, loading, and lubrication. However, in this respect the GRC drivetrain is somewhat limited in its applicability to modern variable-speed drivetrains because of its two-speed, directly gridconnected configuration. Even so, the GRC drivetrain is a valuable platform to investigate reliability issues.

An initial model-to-test comparison of GRC HSS and bearing loads was conducted [12], limited to operation at full-speed and rated power with no rotor moments. Loads predicted by a simple analytic model and a commercial tool were compared to the measured bearing loads. The comparison showed good agreement between shaft torque and bending moments in the upwind section of the HSS and downwind bearing loads. This comparison was recently expanded, focusing on gearbox motion and HSS bending moments, torque, and pinion tooth loads in steady state across a range of power and rotor moments and generator misalignment conditions [13]. Torque, gearbox motion caused by rotor moments, and generator misalignment were found to increase the HSS bending moments near the locating bearings, but they had little effect on HSS pinion loads and bending moments near the HSS pinion. Fully validating HSS loads is a critical 
precursor to examining the HSS bearing loads, which are examined in this report. As an extension to these earlier efforts, this report documents a more comprehensive analysis examining the influence of HSS loads on bearing loads. Two versions of the analytical model are presented and compared to direct bearing load measurement and high-fidelity numerical models. The results are used to evaluate the efficacy of the models and instrumentation and their associated uncertainties and provide insights into stress fields that are important for understanding bearing failures. 


\section{Test Description}

In this section, the relevant properties of the gearbox, HSS, and instrumentation are presented, followed by a discussion of the dynamometer testing conducted over two separate periods from December 2013 to April 2014 and from November 2014 to January 2015 [11]. The GRC gearbox and HSS instrumentation have previously been discussed in great detail [7-13].

\subsection{High-Speed Shaft}

As shown in Figure 1, the HSS was instrumented with strain gauges mounted in full-bridge arrangement at three axial locations. The two orthogonal shaft-bending moments are measured on either side of the high-speed pinion (locations A and B) and downwind of the tapered roller bearing (TRB) pair (location $\mathrm{C}$ ). An additional set of gauges at location $\mathrm{C}$ measures the torque transmitted by the HSS. Shaft-bending and torque measurements were calibrated in-situ [9]. The HSS pinion was also instrumented with two full-bridge strain gauge arrangements for a total of eight measurements, spaced relatively equally along the gear facewidth. A model-to-test comparison of shaft bending, torque, and pinion load distribution was recently completed as a precursor to this report [13].

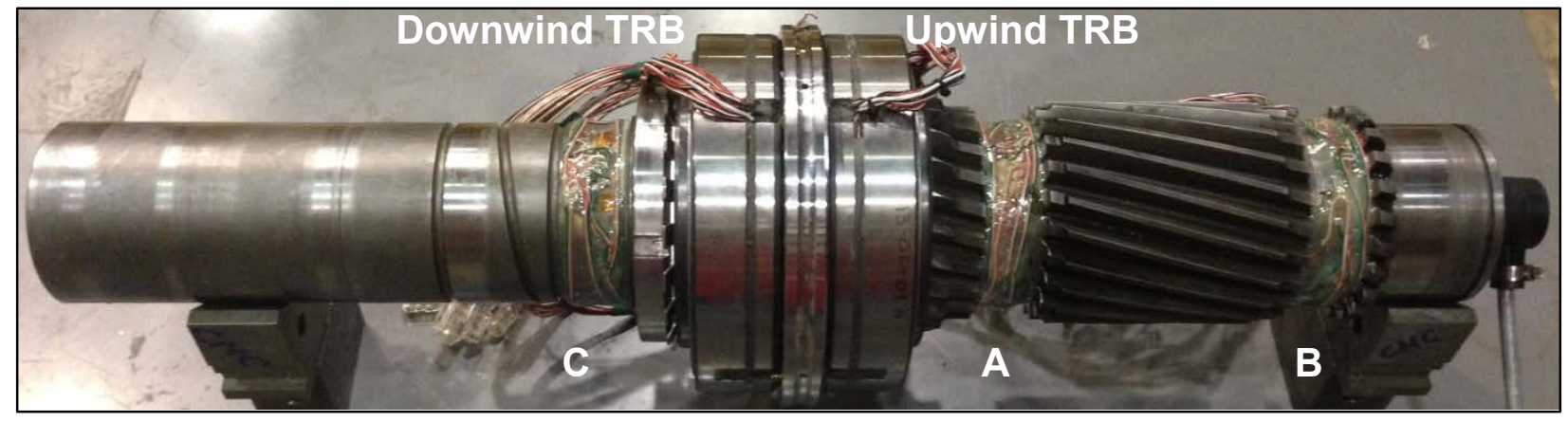

Figure 1. Instrumented high-speed shaft. Photo by Jonathan Keller, NREL 27895

\subsection{High-Speed Shaft Bearings}

The HSS is supported by an NU 2220 E.M1.C3 cylindrical roller bearing (CRB) upwind of the gear mesh [14] and a close-coupled, very lightly preloaded 32222 J2 TRB pair mounted in an Oconfiguration downwind of the gear mesh $[11,12]$. Only the TRBs were instrumented for this work, as they were easily removable and replaceable from the existing gearbox and they support both axial and radial loads. The TRBs have a 200 millimeter $(\mathrm{mm})$ outer diameter, a bore of 110 $\mathrm{mm}$, a total length of $56 \mathrm{~mm}$, and weight of 20 pounds. The TRBs have 20 rolling elements at a $16^{\circ}$ taper angle and their radial static load capacity is 570 kilonewtons $(\mathrm{kN})$. The CRB supports primarily radial load and its outer race would have been very difficult to remove from the existing gearbox, so it was not instrumented in this work.

To facilitate instrumentation of the TRBs, four equally spaced axial grooves were machined in their outer rings. The grooves were cut at an angle that matches the taper angle of the outer ring, with a maximum depth of $10 \mathrm{~mm}$ at the thick end and a width of $15 \mathrm{~mm}$. The axial grooves allow for the actual placement of the gauges, but also serve the purpose of increasing the local strain field to improve gauge response. A $5 \mathrm{~mm}$ wide by $4.2 \mathrm{~mm}$ deep circumferential groove was also machined in the outer ring to allow for routing of the wiring to one location, which serves as the 
exit point from the bearing face out through the gearbox housing. Finally, a small hole was machined in the thick end of each outer race so that a pin could be installed between each bearing, serving as a key. Strain gauges installed on the TRB outer rings measure radial loads in the remaining "bridge" of bearing race material as the rollers move underneath it and deflect it. Gauge pairs, wired in a Poisson half-bridge configuration, are located at two different axial locations in each of the four grooves for a total of eight gauge pairs per bearing. The axial locations are at $9 \mathrm{~mm}$ and $24 \mathrm{~mm}$ from the thick end of the $46 \mathrm{~mm}$ wide outer race, equating to measurements at $20 \%$ and just over $50 \%$ of the bearing outer race width as shown in Figure 2.Additionally, a resistance temperature detector (not shown here) measures the outer ring temperature.

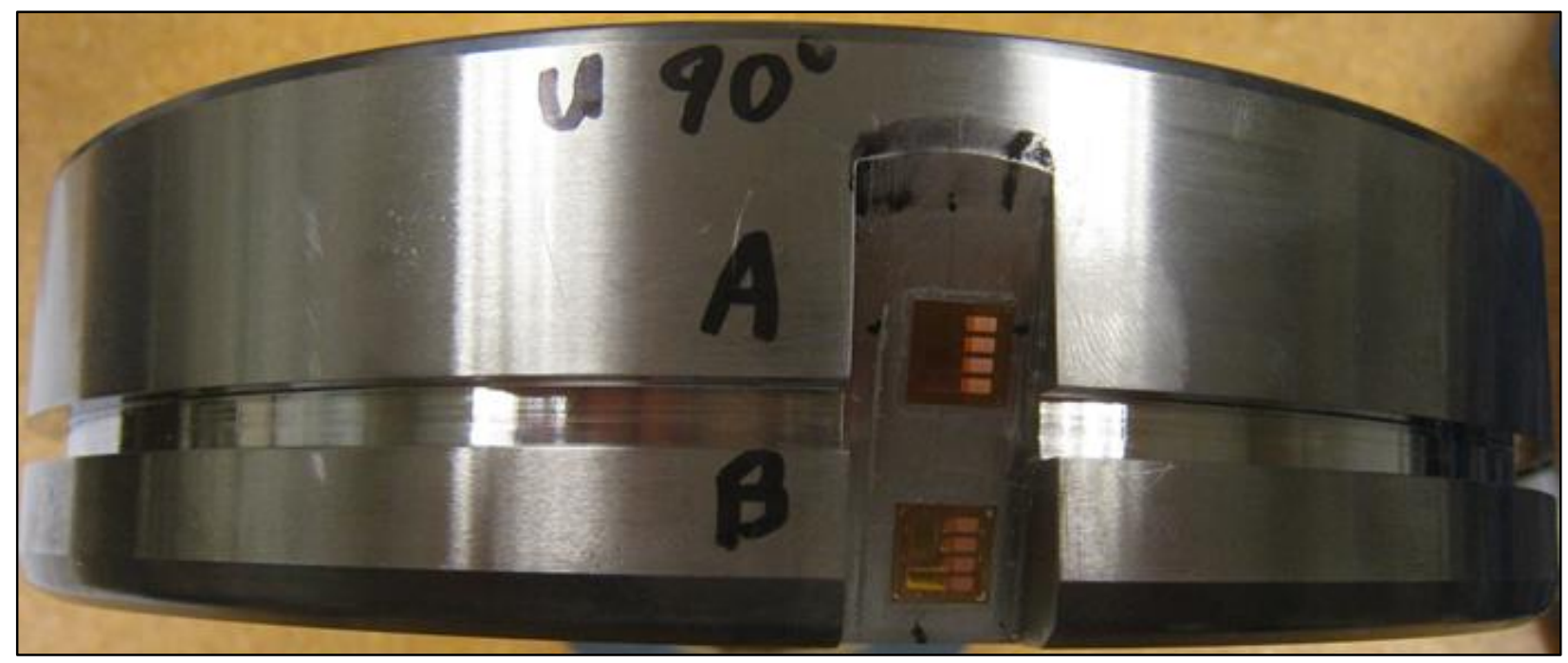

Figure 2. Downwind tapered roller bearing instrumentation. Photo by Jonathan Keller, NREL 37697

The two axial locations provide an indication of the load distribution across the axial width of the ring. The axial locations were selected to be well within the contact area between the roller and ring, while still providing enough room for the wires between the ring and the gearbox housing. The four circumferential locations provide a coarse indication of the load zone distribution around the bearing outer ring. Instrumenting both the upwind and downwind TRBs gives an indication of the load share between the TRBs. The bearing strain gauges were calibrated in a special fixture representative of the gearbox housing and HSS [10] prior to mounting the bearings on the instrumented HSS and installing the assembly into the gearbox for dynamometer testing [11-12].

\subsection{Dynamometer Testing}

The National Wind Technology Center (NWTC) 2.5-megawatt (MW) dynamometer test facility was used for Phase 3 testing to enable load application to the GRC drivetrain under controlled conditions. The Phase 3 test program included steady-state and transient test conditions [11]. This report is limited to the steady-state conditions for various combinations of torque, rotor moments, and misalignment of the generator [13]. All tests discussed herein were conducted while the drivetrain was operating at the full speed of 1800 revolutions per minute (rpm) on the HSS. In all cases, the HSS data were acquired at 2 kilohertz $(\mathrm{kHz})$ for 1 second, equating to 30 shaft revolutions per acquisition. 


\section{Model Description}

This section presents three different models used to examine HSS bearing loads for comparison to the measurements described in the previous section. The models are differentiated by their modeling complexity, the level of fidelity in predicting bearing loads, and ability to model timevarying or only steady-state conditions.

The first is a simple analytical model, which, through force and moment equilibrium at each instant in time, derives only the total bearing loads from measured shaft-bending moments and torque. The analytical model serves as an efficient mechanism to understand the underlying physical behavior of the system. The second is a SIMPACK multibody model, which represents the bearings as spring-damper elements. The specified bearing stiffnesses and predicted bearing displacements are then used to calculate the total bearing loads. The third and last is a Transmission3D, full-finite element model, which predicts the bearing load zone and contact pressure in addition to the total bearing load. The contact pressure within the bearings is of specific interest relative to the bearing white-etching area crack failure mode [5].

\subsection{Analytic Model}

An analytical model was previously developed and initially examined in just one operational condition [12]. In this report, two variations of the analytic model are developed based on a key difference in how the locating bearing pair supports the HSS. In the analytic model, the HSS is supported by the generator coupling and a number of bearings, each of which is treated as an unknown reaction. These unknown total bearing forces and moments are then determined by solving the force and moment equations satisfying static equilibrium at each instant in time using the measured shaft torque and bending moments. As such, it can be considered a quasi-static model. Initial model assumptions are:

- The HSS is rigid and its weight is negligible

- The CRB does not carry a bending moment or react axial force

- The generator coupling reacts only moments.

The following sections describe the assumptions relating to the locating bearing pair for each model variation. The locating bearing pair, as a unit, reacts the axial and radial mesh forces as well as bending moments arising from the mesh forces and external influences from the generator coupling.

\subsubsection{Locating Bearing Pair Modeled as a Single Element}

In the first model variation, the locating bearing pair is modeled as a single element, so it is not possible to predict the load share between the TRBs. This element supports axial and radial forces as well as bending moments. The free-body diagram of the HSS for this variation is shown in Figure 3. Note these are the forces and moment applied to the HSS itself. For example, the HSS rotates in the clockwise $(+x)$ direction and supplies positive torque to the generator; however, the generator resists with an equivalent torque in the counterclockwise $(-x)$ direction. 


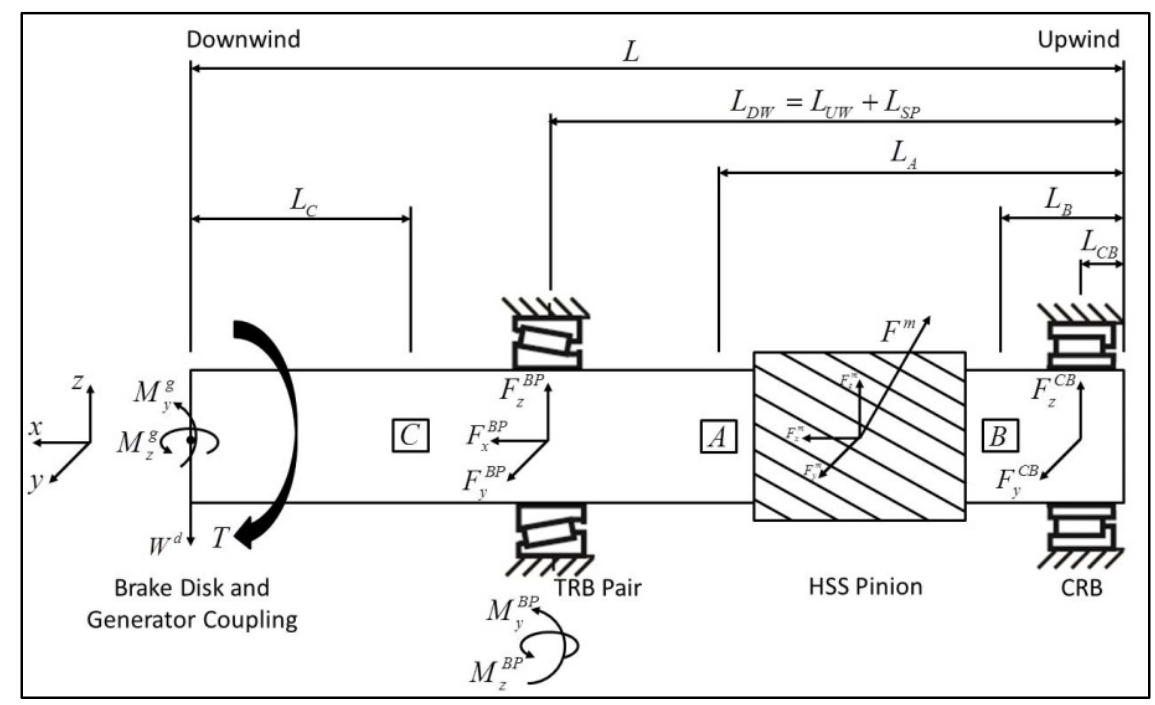

Figure 3. HSS free-body diagram for locating bearing pair modeled as a single element

The 10 unknowns can be solved from the 10 equilibrium equations that can be written: torque equilibrium, force equilibrium in three directions, and moment equilibrium at the three locations $(\mathrm{C}, \mathrm{A}$, and $\mathrm{B})$ in two directions. Beginning with torque equilibrium, the mesh force is:

$$
\begin{aligned}
& F^{m}=\frac{T}{R_{b} \cos \beta} \\
& F_{x}^{m}=\frac{T}{R_{b}} \tan (\phi \beta) \quad\left\{\begin{array}{c}
\phi=+1 \text { for left hand helix } \\
\phi=-1 \text { for right hand helix }
\end{array}, \quad F_{y}^{m}=-\frac{T}{R_{b}} \sin \gamma, \quad F_{z}^{m}=\frac{T}{R_{b}} \cos \gamma\right.
\end{aligned}
$$

Moment equilibrium at location $\mathrm{C}$ yields the moments applied by the generator coupling and brake disk weight. These moments result primarily from any static and operational misalignment [13]. Similar to the torque, all the measured moments are in terms of those applied to the HSS.

$$
\begin{aligned}
& M_{y}^{g}=-M_{y}^{C}-W^{d} L_{C} \\
& M_{z}^{g}=-M_{z}^{C}
\end{aligned}
$$

Moment equilibrium at location $\mathrm{B}$ yields the $\mathrm{CRB}$ reactions:

$$
\begin{aligned}
& F_{y}^{C B}=+\frac{M_{z}^{B}}{L_{B}-L_{C B}} \\
& F_{z}^{C B}=-\frac{M_{y}^{B}}{L_{B}-L_{C B}}
\end{aligned}
$$

Axial force equilibrium and moment equilibrium at location A yields the TRB reactions: 


$$
\begin{aligned}
& F_{x}^{B P}=-\frac{T}{R_{b}} \tan (\phi \beta) \\
& F_{y}^{B P}=+\frac{T}{R_{b}} \sin \gamma-\frac{M_{z}^{B}}{L_{B}-L_{C B}} \\
& F_{z}^{B P}=-\frac{T}{R_{b}} \cos \gamma+\frac{M_{y}^{B}}{L_{B}-L_{C B}}+W^{d} \\
& M_{y}^{B P}=M_{y}^{C}-M_{y}^{A}-\left(\frac{T}{R_{b}} \cos \gamma-\frac{M_{y}^{B}}{L_{B}-L_{C B}}\right)\left(L_{D W}-L_{A}\right)-W^{d}\left(L-L_{C}-L_{D W}\right) \\
& M_{z}^{B P}=M_{z}^{C}-M_{z}^{A}-\left(\frac{T}{R_{b}} \sin \gamma-\frac{M_{z}^{B}}{L_{B}-L_{C B}}\right)\left(L_{D W}-L_{A}\right)
\end{aligned}
$$

\subsubsection{Locating Bearing Pair Modeled as Individual Elements}

In the second model variation, the locating bearing pair is modeled as individual bearing elements. In this formulation, additional assumptions about the behavior of the locating bearing pair are required to achieve a tractable solution. Those assumptions are:

- The upwind TRB does not carry any axial load, because it is not restrained by the housing due to a manufacturing error [13].

- The TRBs do not carry bending moments, because their radial stiffnesses are much greater than their tilting stiffnesses [13].

As a result, the load share between the TRBs can be determined with this analytic formulation, but it is subject to the validity of these assumptions. The resulting free-body diagram of the HSS for this variation is shown in Figure 4.

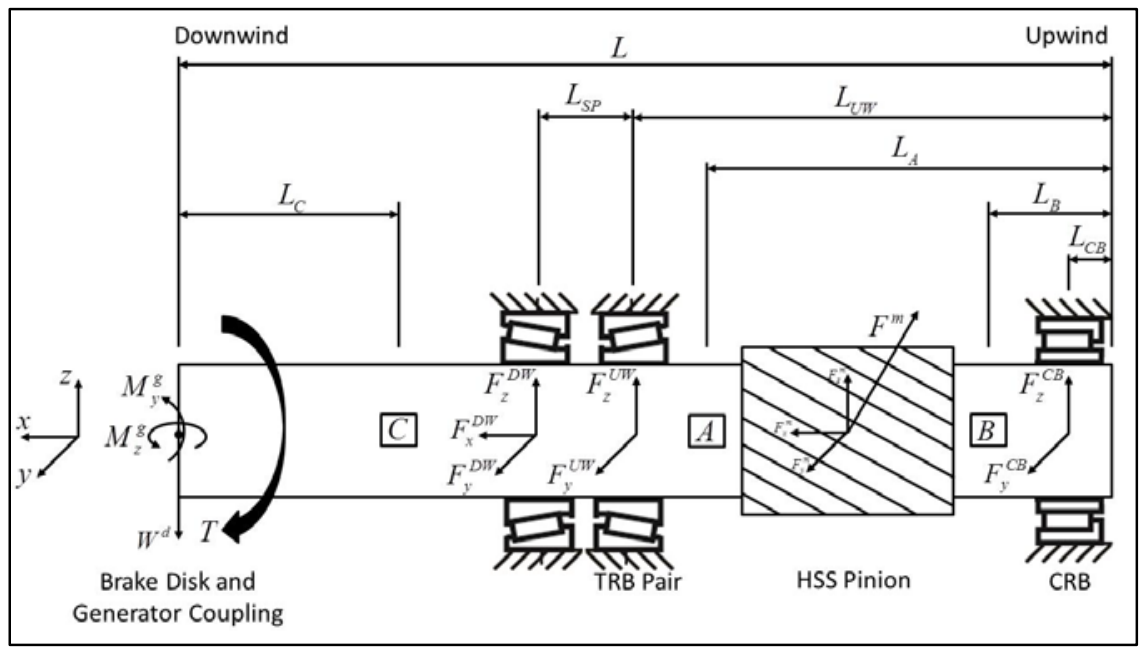

Figure 4. HSS free-body diagram for locating bearing pair modeled as individual elements 
The 10 unknowns can again be solved from the 10 equilibrium equations that can be written. The torque equilibrium, mesh forces, generator reactions, and CRB reactions are identical to the first formulation. The reactions at the upwind TRB are:

$$
\begin{aligned}
& F_{y}^{U W}=\frac{-1}{L_{S P}}\left[M_{z}^{C}-M_{z}^{A}-\left(\frac{T}{R_{b}} \sin \gamma-\frac{M_{z}^{B}}{L_{B}-L_{C B}}\right)\left(L_{S P}+L_{U W}-L_{A}\right)\right] \\
& F_{z}^{U W}=\frac{1}{L_{S P}}\left[M_{y}^{C}-M_{y}^{A}-\left(\frac{T}{R_{b}} \cos \gamma-\frac{M_{y}^{B}}{L_{B}-L_{C B}}\right)\left(L_{S P}+L_{U W}-L_{A}\right)-W^{d}\left(L-L_{C}-L_{S P}-L_{U W}\right)\right]
\end{aligned}
$$

The reactions at the downwind TRB are:

$$
\begin{aligned}
& F_{x}^{D W}=-\frac{T}{R_{b}} \tan (\phi \beta) \\
& F_{y}^{D W}=\frac{1}{L_{S P}}\left[M_{z}^{C}-M_{z}^{A}-\left(\frac{T}{R_{b}} \sin \gamma-\frac{M_{z}^{B}}{L_{B}-L_{C B}}\right)\left(L_{U W}-L_{A}\right)\right] \\
& F_{z}^{D W}=\frac{-1}{L_{S P}}\left[M_{y}^{C}-M_{y}^{A}-\left(\frac{T}{R_{b}} \cos \gamma-\frac{M_{y}^{B}}{L_{B}-L_{C B}}\right)\left(L_{U W}-L_{A}\right)-W^{d}\left(L-L_{C}-L_{U W}\right)\right]
\end{aligned}
$$

The downwind bearing supports all the axial gear mesh load, so equation (13) is identical to equation (6) even though the nomenclature is slightly different.

\subsubsection{Gearbox Properties for the Analytic Model}

For each model, the properties of the GRC HSS are $L=775 \mathrm{~mm}, R_{b}=53.0727 \mathrm{~mm}, \alpha=20^{\circ}, \phi=$ -1 and $\beta=14^{\circ}$. The points of action of the bearings are $L_{C B}=33$ - millimeters $(\mathrm{mm}), L_{U W}=333.5$ $\mathrm{mm}$, and $L_{S P}=79 \mathrm{~mm}$. The instrumentation locations are $L_{A}=260.5 \mathrm{~mm}, L_{B}=88.5 \mathrm{~mm}, L_{C}=$ $298 \mathrm{~mm}$ [9]. Unique to this formulation is the angle $\gamma$, which is the direction of the line of action connecting the base circles between the intermediate high-speed gear and the high-speed pinion relative to the vertical $(+z)$ axis. This angle determines the magnitude and direction of the mesh vertical and lateral forces and can be determined from the gearbox housing and high-speed pinion drawing of each gear. For the GRC gearbox, $\gamma=-10.207^{\circ}$, as shown in Figure 5. 


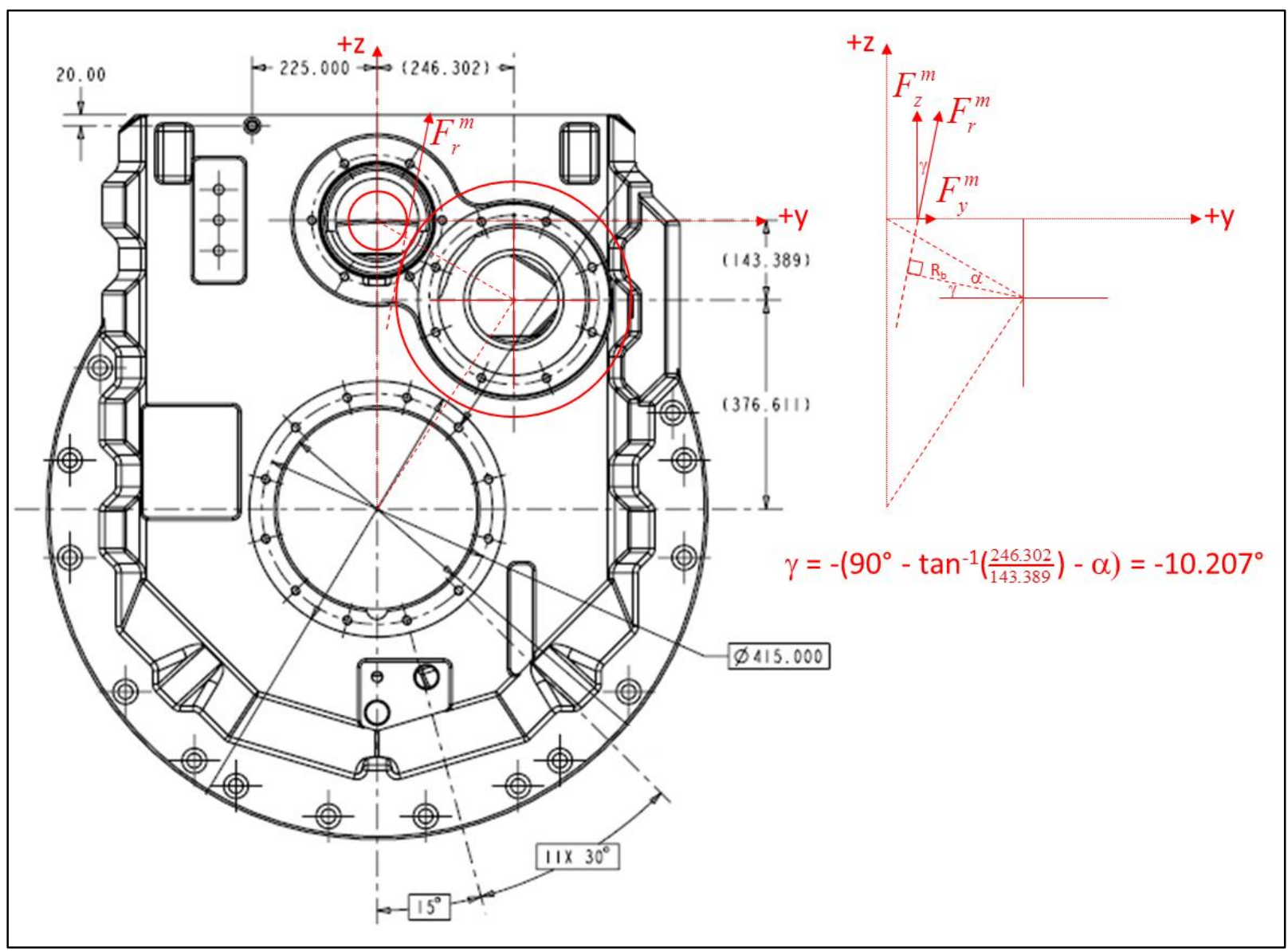

Figure 5. Line of action for the GRC gearbox

\subsection{Multibody Model}

A multibody model of the GRC gearbox was previously developed in SIMPACK [12]. A more detailed model of the HSS, gearbox bushings, and generator coupling was also developed and compared to the experimental data [13]. For completeness, additional details of the bearing stiffnesses are presented along with sample results in this section.

\subsubsection{High-Speed Shaft}

The HSS is modeled as shown in Figure 6 as a hollow, circular structure defined by a nodebased, nonlinear, finite difference approach. Each section of the shaft is defined by its cross section connecting the two nodes with 6 degrees of freedom per node. Twenty-two nodes were used to define the HSS, which was supported at the mesh interface and the three bearing force elements. Node 1 represents the HSS pinion and intermediate gear mesh. Nodes 8, 9, and 21 represent the locations of the TRB pair and the CRB. Node 16 is the location brake disk and generator coupling. Nodes 3, 10, and 18 are the locations of the strain gauges at A, C, and B. 


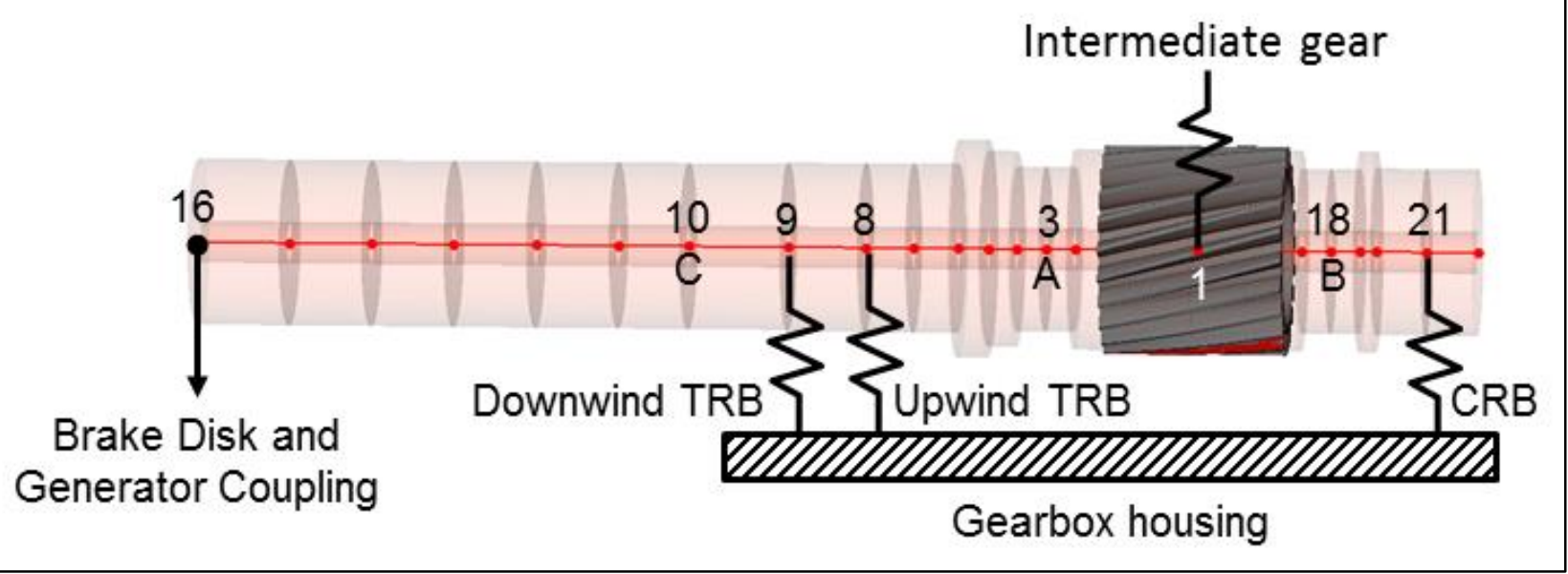

Figure 6. SIMPACK model of the HSS

\subsubsection{High-Speed Shaft Bearings}

The bearings were modeled as viscoelastic spring-damper elements, with clearance and stiffnesses defined using a force-displacement relationship. A parametric study was completed to determine the stiffness characteristics of the HSS bearings. The point of action of the downwind TRB was assumed to be at its front edge $(386 \mathrm{~mm})$, the CRB stiffness factor was chosen as x 10, and the upwind TRB stiffness factor was chosen as 0.1. The final HSS bearing model characteristics are listed in Table 1 [13].

Table 1. Modeled Stiffnesses of HSS Bearings

\begin{tabular}{|l|c|c|c|}
\hline & Downwind TRB & Upwind TRB & CRB \\
\hline Axial Location ${ }^{\dagger}, \mathrm{mm}$ & $386^{\ddagger}$ & 333.5 & 33 \\
\hline Axial Stiffness, $(\mathrm{N} / \mathrm{m})$ & $1.3 \times 10^{9}$ & $4.7 \times 10^{8}$ & 0 \\
Radial- $y$ Stiffness, $(\mathrm{N} / \mathrm{m})$ & $8.0 \times 10^{9}$ & $3.1 \times 10^{8 \ddagger}$ & $4.7 \times 10^{10 \ddagger}$ \\
Radial-z Stiffness, $(\mathrm{N} / \mathrm{m})$ & $8.0 \times 10^{9}$ & $2.9 \times 10^{8} \ddagger$ & $4.6 \times 10^{10 \ddagger}$ \\
\hline Tilt-y Stiffness, $(\mathrm{Nm} / \mathrm{rad})$ & $3.3 \times 10^{6}$ & $0.9 \times 10^{6}$ & $2.9 \times 10^{5}$ \\
Tilt-z Stiffness, $(\mathrm{Nm} / \mathrm{rad})$ & $3.3 \times 10^{6}$ & $1.1 \times 10^{6}$ & $3.0 \times 10^{5}$ \\
\hline \hline
\end{tabular}

tLocation specified from the upwind end of the HSS

‡Location and stiffness values tailored through analysis

\subsubsection{High-Speed Shaft Torque and Bending Moments}

The SIMPACK model predicts HSS torque relative to the input main shaft torque measured during each test. HSS torque is the primary factor driving HSS forces and bending moments and the HSS bearing loads, so accurate prediction of torque is of interest. Figure 7 compares the torque over one shaft revolution at the different power levels [13]. As expected, the shaft torque increases linearly from nearly zero with the generator offline to $4.25 \mathrm{kNm}$ at rated power. Although the SIMPACK results have an essentially constant magnitude over the shaft revolution, the experimental measurements show a consistent $\pm 0.4 \mathrm{kNm}$ variation ( $\pm 10 \%$ of full power). Neither the main shaft input torque nor speed shows a similar variation, so they are not the cause 
of it. A possible source for this variation has been hypothesized as tooth-spacing errors on the pinion [15]. Regardless of its source, this HSS torque variation is expected to drive a similar magnitude variation in HSS shaft and bearing loads.
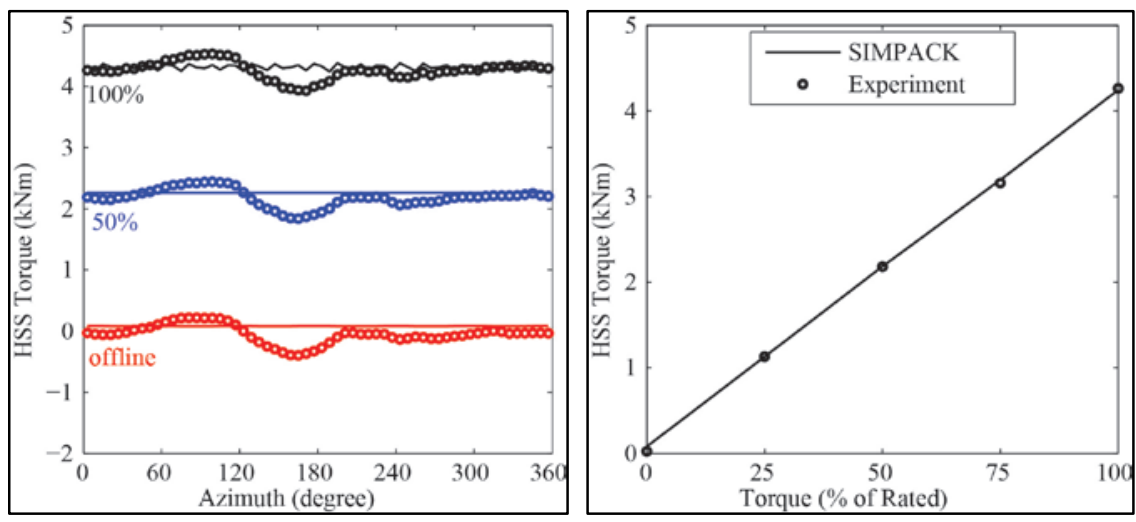

Figure 7. Variation in HSS torque with power [13]

A comparison of the measured and predicted bending moments in pure torque conditions is shown in Figure 8. The bending moments near the HSS pinion, locations A and B, increase linearly with power. This is expected, as the gear mesh contact forces increase linearly with power and greatly influence the loading behavior in the immediate vicinity of the pinion. This bending moment is also nearly constant over the shaft revolution. The measured bending moment at location $\mathrm{C}$, in contrast, only changes slightly with power. The main contributor to this bending moment is due to the moment of $0.4 \mathrm{kNm}$ induced by the brake disk and generator coupling weight [13] and is affected to a lesser extent by gearbox motion as torque is applied. The variation over the shaft rotation is on the order of $\pm 0.3 \mathrm{kNm}$ as a result of the generator coupling. The SIMPACK model predicts a near-constant moment over the shaft revolution, increasing slightly with power because of the additional gearbox motion-induced moment.
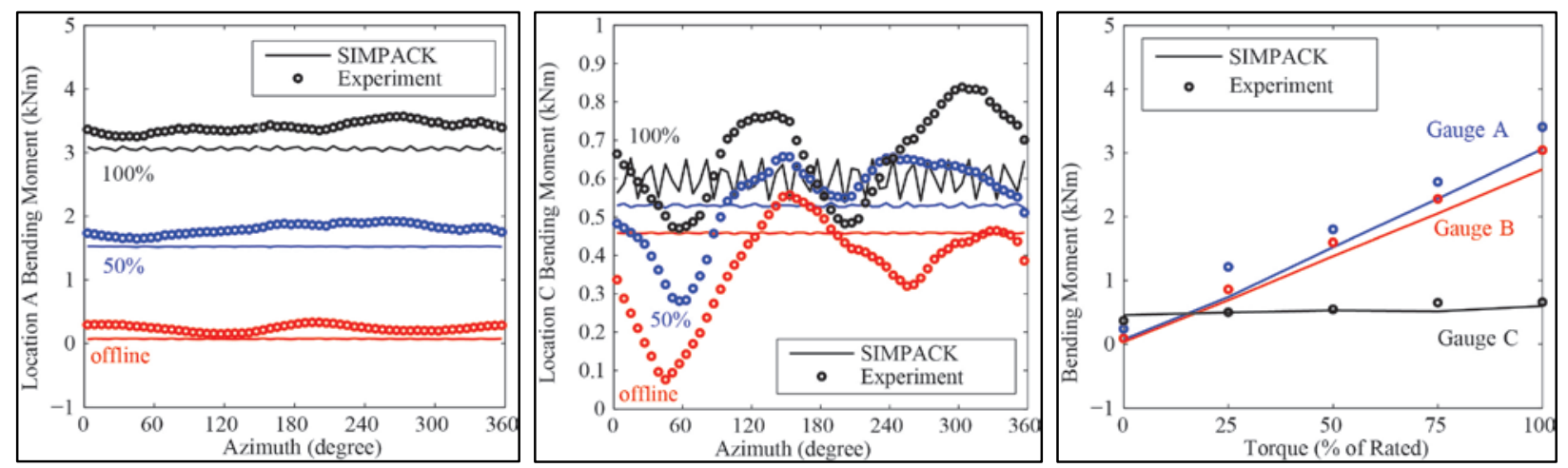

Figure 8. Variation of HSS bending moments with power [13]

\subsection{Finite-Element/Contact Mechanics Model}

Transmission3D is a linear finite-element/contact mechanics program designed for the analysis of multimesh gear drivetrains and can model the entire drivetrain as deformable bodies. Efficient modeling of gear and bearing contact mechanics is a feature of Transmission3D. Traditional finite-element programs are ill-suited for this application because the contact area is orders of magnitude smaller than the dimensions of the contacting bodies. The contacts are also influenced 
by microgeometries on the scale of microns. Modeling these features would require a highly refined finite-element mesh over the entire contact zone or would require the localized contact elements to be remeshed at each rotating position because the contact area moves across the body as it rotates. Either approach greatly increases computation time. Transmission3D computes these contacts relatively efficiently by utilizing a hybrid algorithm of finite elements to predict far field displacements and a Green's Function model to predict relative displacements local to the contact region [16].

The Transmission3D model of the HSS is shown in Figure 9. The gears, bearing raceways, and rollers were modeled using finite elements. Crowning on the bearing rollers and races, clearance, and preload were included. The brake disk weight is included in the model. Operational misalignment occurring at higher torques is not included; however, the additional bending moments applied to the downwind end of the HSS are small compared to the bending moments due to the gear mesh force [13].The Transmission3D model was also used to design the grooves in the TRBs, and predicted strain levels were compared to initial measurements [13,17]. A comprehensive comparison of predicted bearing load zones with measured data, along with examination of bearing stresses, is the primary goal of this work.

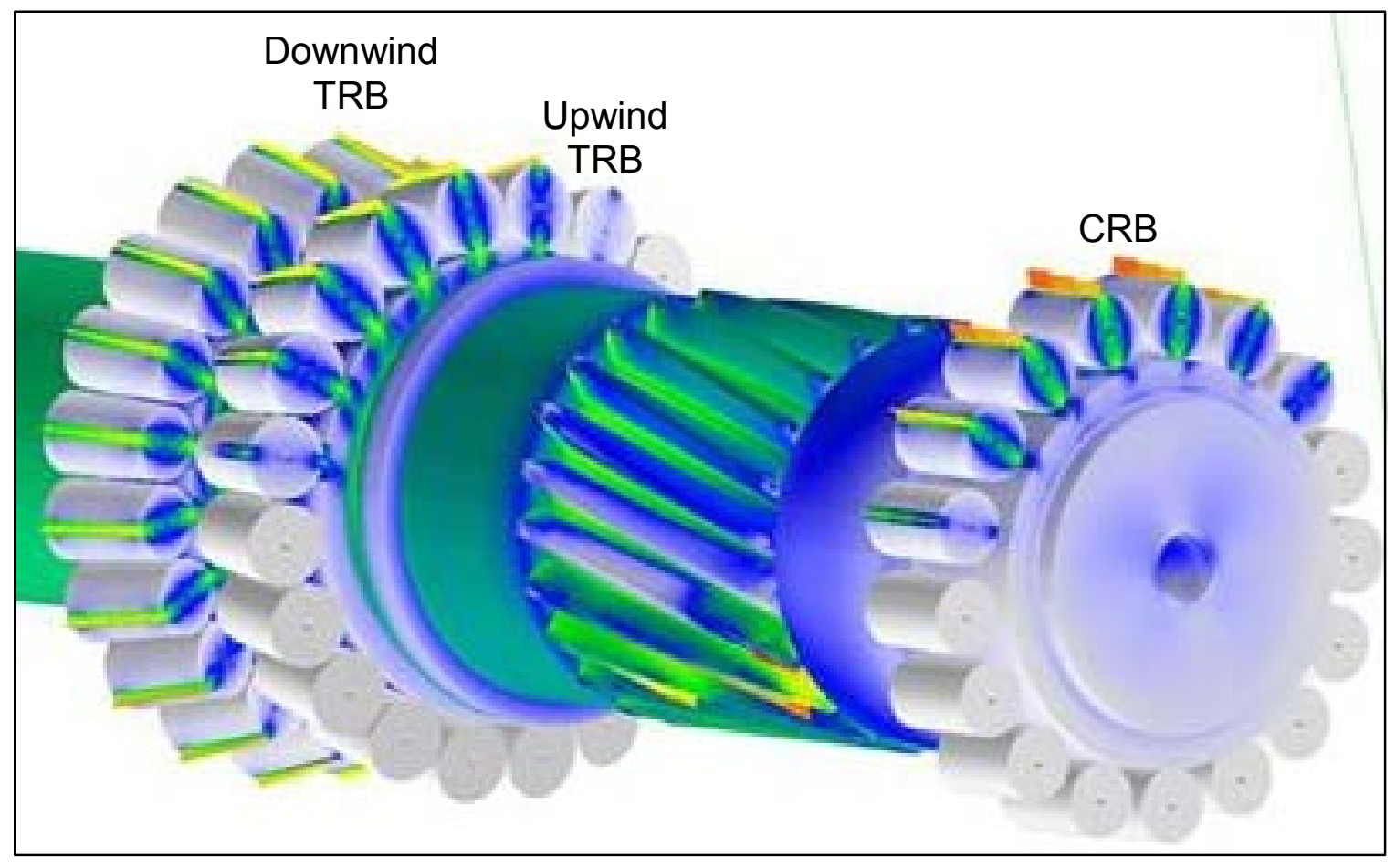

Figure 9. Transmission3D finite-element model of the high-speed shaft 


\section{Results}

This section presents the model-to-test comparison for the HSS bearing loads, including the load zone and total load for each bearing. Steady-state operation at different load levels is examined first, along with the effect of nontorque loads and generator misalignment on the HSS bearings. For the models, the average torque and nontorque loads measured during the tests were used as input conditions. The section concludes with an examination of the bearing stresses for the GRC gearbox as they relate to bearing axial cracking.

\subsection{Bearing Load Zones}

A discussion of the processing of the bearing direct measurements is presented first, followed by a comparison of the resulting bearing load zones to the Transmission3D finite element model. The bearing load zones are then used to determine the total measured bearing loads that are compared to the SIMPACK and analytical models.

\subsubsection{Bearing Strain and Load Measurements}

The strain measurement that results when the bearing rollers pass beneath the strain gauges mounted on the outer raceway is a sinusoid-like signal. A 0.1 -second portion of two strain measurements at full power is shown in Figure 10. The measurements are at the $20 \%$ bearing axial width and $90^{\circ}$ circumferential location for the downwind TRB, and $50 \%$ width and $0^{\circ}$ circumferential location for the upwind TRB. Each individual peak occurs when a roller passes underneath the strain gauge, while a valley occurs when the rollers are equidistant from the strain gauge. In addition to the high-frequency sinusoid, there is a much lower frequency variation related to the HSS rotational speed. For the downwind bearing, the signal maximum is relatively constant but the minimum is not. For the upwind bearing, both the maximum and minimum vary at approximately the once-per-revolution frequency of the HSS $(30 \mathrm{~Hz}$, or three times per 0.1 second). These variations are likely to be related to the $10 \%$ variation in measured HSS torque shown in Figure 7.
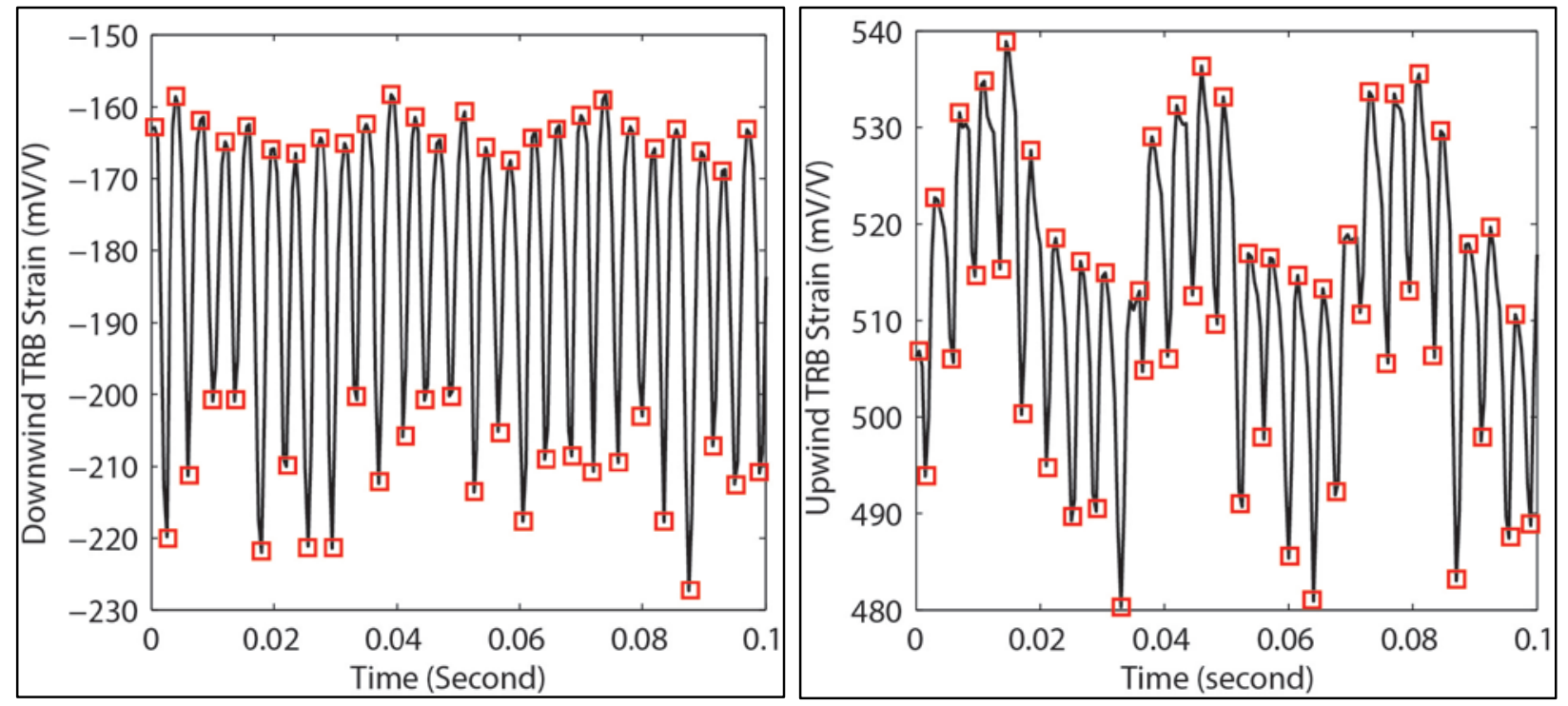

Figure 10. Example downwind (left) and upwind (right) TRB strain gauge measurements 
The first step in the signal processing is to calculate the peak-to-valley amplitude (range). The ranges for the same two bearings are shown in Figure 11 over the full 1-second acquisition. Note that processing effectively downsamples the data from the $2,000-\mathrm{Hz}$ acquisition rate to the 255 $\mathrm{Hz}$ outer race roller pass frequency for the bearing. The processed ranges are then converted to load, in $\mathrm{kN}$, at each circumferential location by applying a calibration factor and offset as shown in Figure 12 [10]. The loads can only be calculated at the outer race roller pass frequency. The mean loads for these circumferential locations are 8.0 and $3.6 \mathrm{kN}$, but there is significant timevariation in the loads. This time variation in the direct measurement is one source of uncertainty in determining the total measured bearing load. Figure 11 and Figure 12 indicate that some amount of time averaging is required to determine the bearing load; that is, it is unlikely the measured bearing load can be calculated at every instant in time.
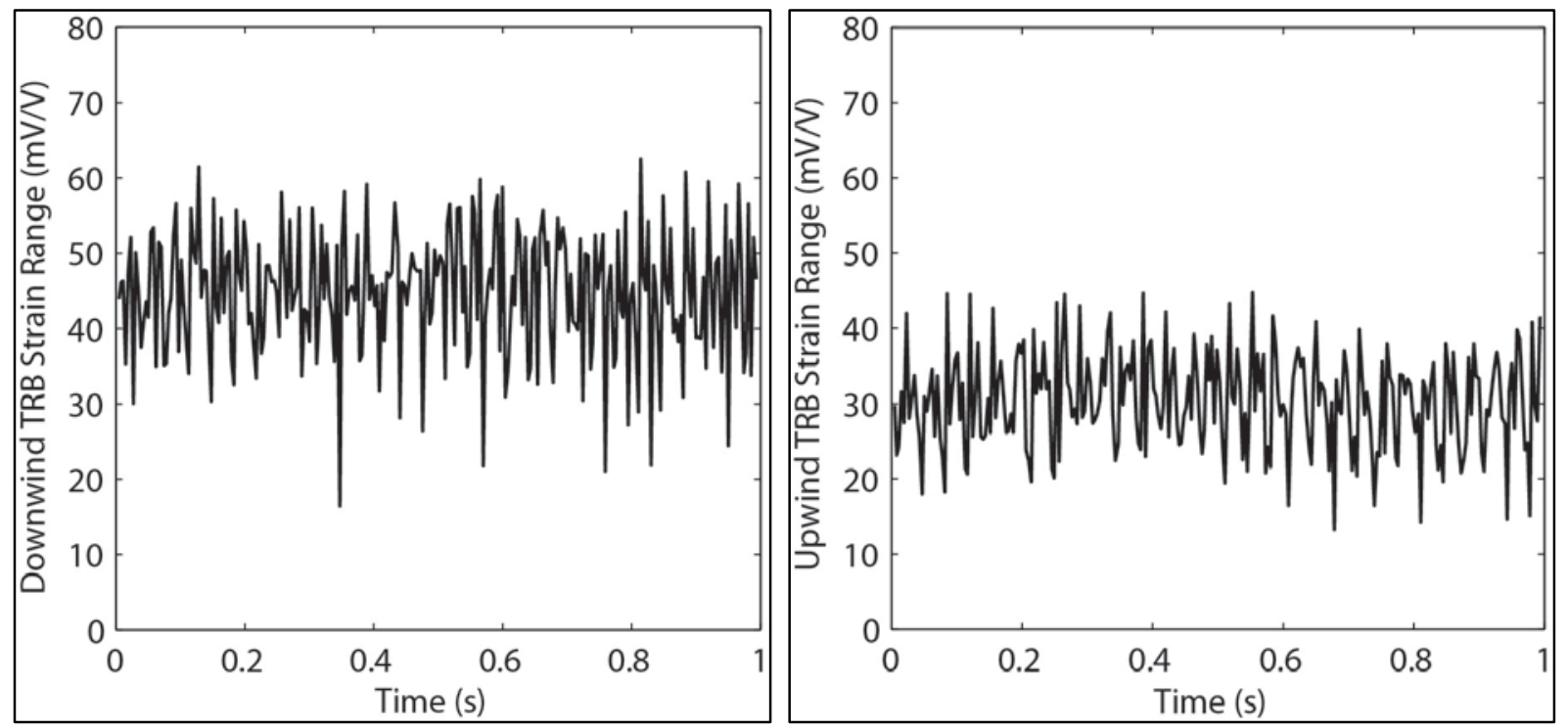

Figure 11. Example downwind (left) and upwind (right) TRB strain range measurements
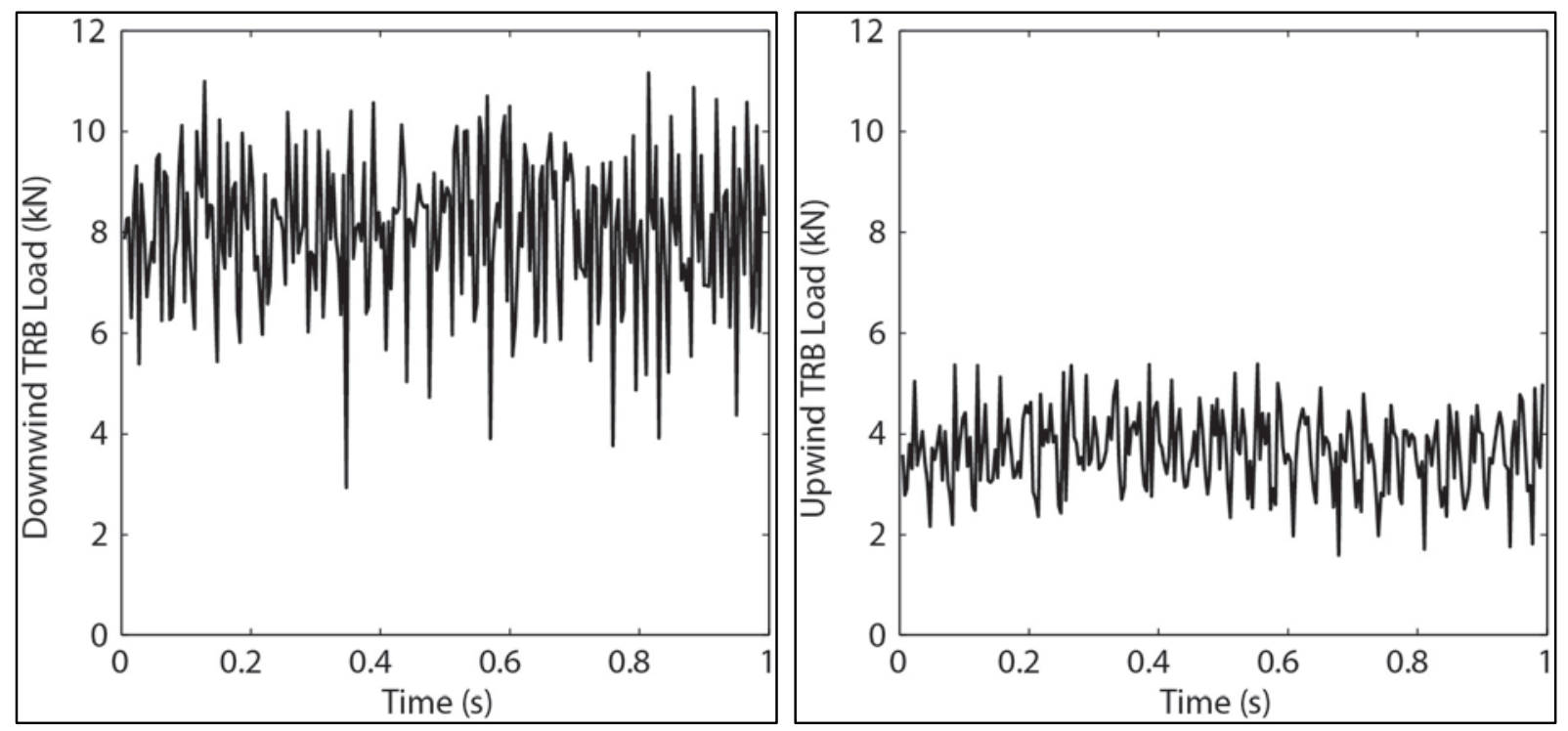

Figure 12. Example downwind (left) and upwind (right) TRB load measurements 


\subsubsection{Bearing Load Zone Measurements}

The mean load measured during each 1-second acquisition is compared to the Transmission3D model in Figure 13 to Figure 15 for offline, 50\% power, and 100\% power conditions, respectively. Each figure is shown when viewed from upwind, with the HSS rotating in the clockwise direction. In each case, the test condition was with no nontorque load applied to the gearbox and no induced generator misalignment. Two sets of experimental measurements are shown on each plot, corresponding to the two axial locations. Multiple data acquisitions are shown for each condition. In this case, the test acquisitions occur before and after large main rotor pitching moments were applied to the drivetrain, resulting in some amount of residual operational misalignment due to hysteresis in the gearbox elastomeric bushings [13].

Overall, the agreement between the model and experimental results is good for both bearings. The load zone is very small in offline conditions and grows as torque is applied, as expected. In each case the upwind TRB has only a few rollers in contact, whereas the downwind TRB has all rollers in contact. This is primarily because the gear-mesh force pulls the shaft upwind, resulting in an axial load that is reacted by the downwind bearing. Thus, the downwind bearing is reacting both axial and radial loads, while the upwind bearing is primarily reacting only a radial load. The unequal load sharing between the two bearings also has other contributing factors. The TRB pair was designed with very little preload, provided only by small springs located between the outer races. This effect is evident in both bearings in offline conditions as shown in Figure 13, where there is very little measured load. It should be noted that although the generator was offline, there is a small amount torque in the HSS due to frictional losses and bending in the HSS due to brake disk weight. Additionally, the gearbox housing has a manufacturing error in the counterbore, so the upwind bearing is not retained axially [9]. This is the likely explanation of the large amount of variability in the upwind bearing measured load zone in offline conditions.

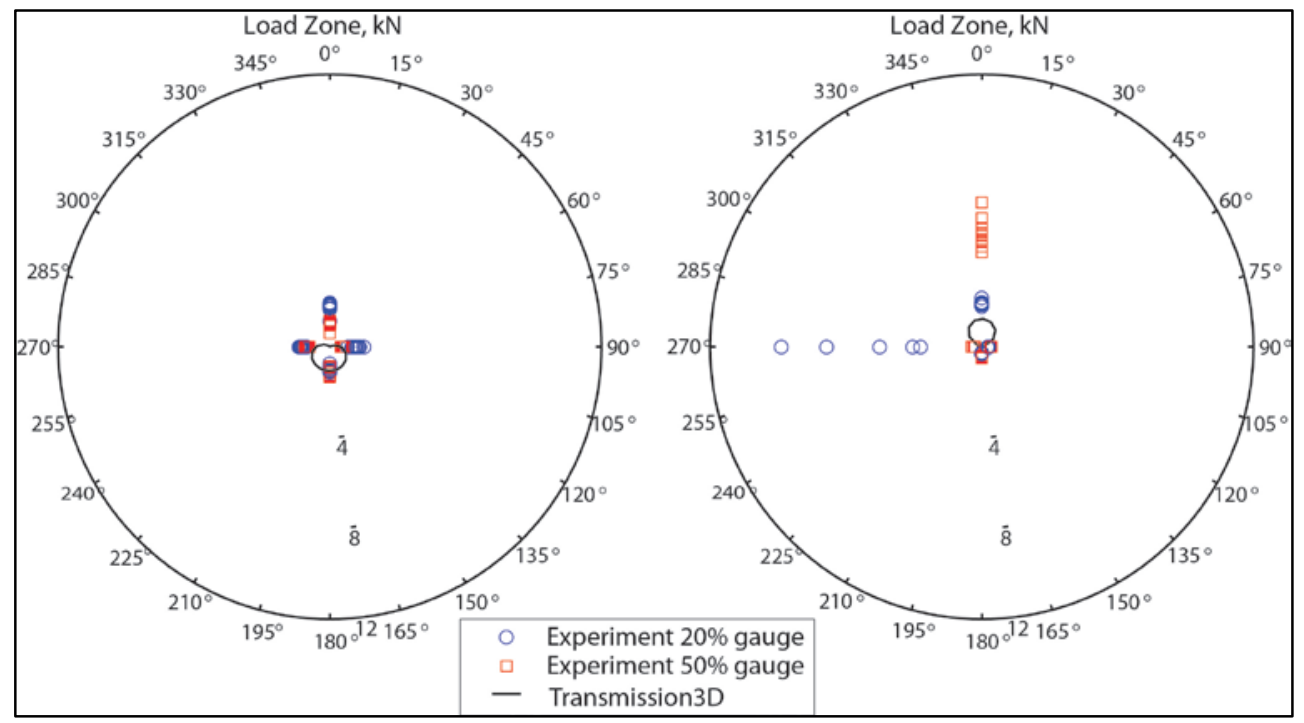

Figure 13. Downwind (left) and upwind (right) TRB load zones in offline conditions

As $50 \%$ power is applied in Figure 14, the effect of the gear-mesh force dominates the shape of the load zones. The effect of the mesh force is most apparent in the upwind TRB load zone. As shown in Figure 5, the gear-mesh force line of action is $\gamma=-10.2^{\circ}$ (or $349.8^{\circ}$ ). For this bearing, only the strain gauges at the $0^{\circ}$ circumferential location experience any load. The upwind TRB 
strain gauges at $90^{\circ}, 180^{\circ}$, and $270^{\circ}$ experience essentially no load at all. Likewise, the Transmission3D model shows only the area from approximately $315^{\circ}$ to $15^{\circ}$ is loaded.

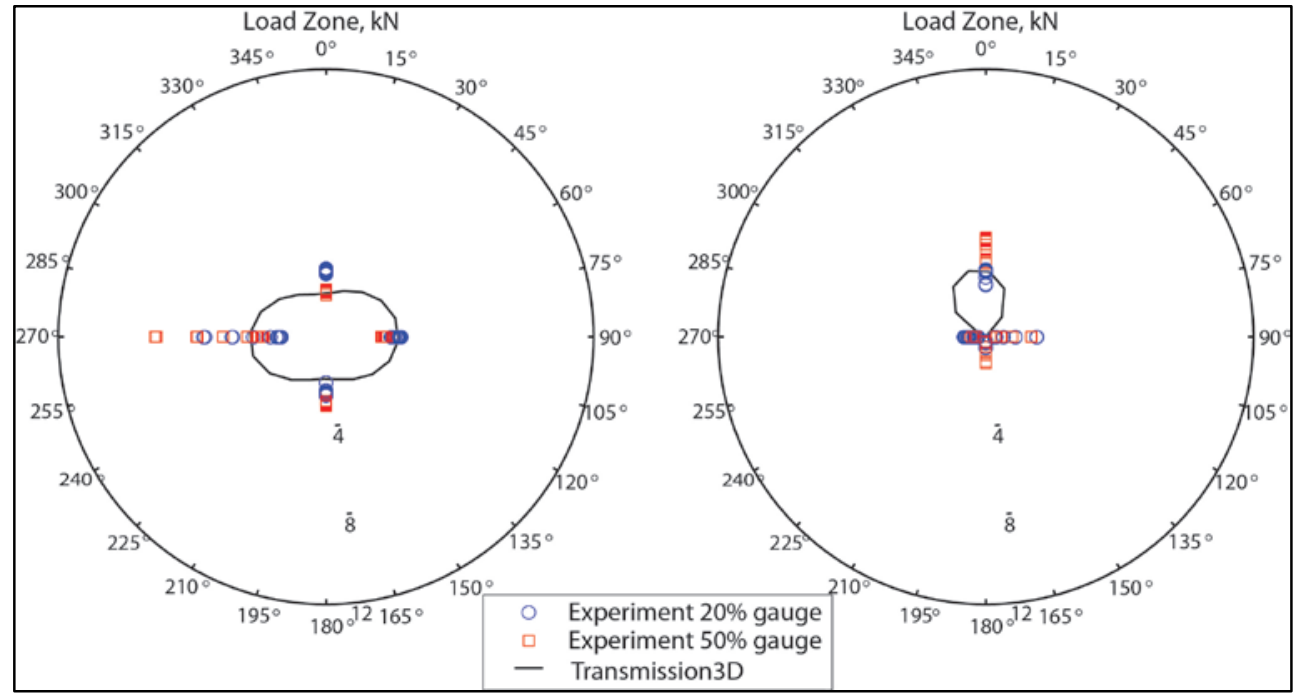

Figure 14. Downwind (left) and upwind (right) TRB load zones at $50 \%$ power

Because the downwind TRB supports both radial and axial loads, its load zone is elliptical in shape. This is indicated by both the measurements and the Transmission3D model and is most evident at $100 \%$ power as shown in Figure 15. Although the downwind TRB load zone is quite large, it is almost centered on the origin and symmetric, indicating that the total radial load it supports is relatively small. At full power for the downwind TRB, the $20 \%$ and $50 \%$ strain gauge measurements are significantly different at the $90^{\circ}$ circumferential location. This indicates that the bearing race tilted during operation because the small preload cannot limit the relative motion between the rollers and raceways. The Transmission3D model predicts roughly the average of the two measurements at this location. The upwind TRB load zone is smaller; however, it is not centered at the origin so the bearing supports a significant radial load from the gear mesh.

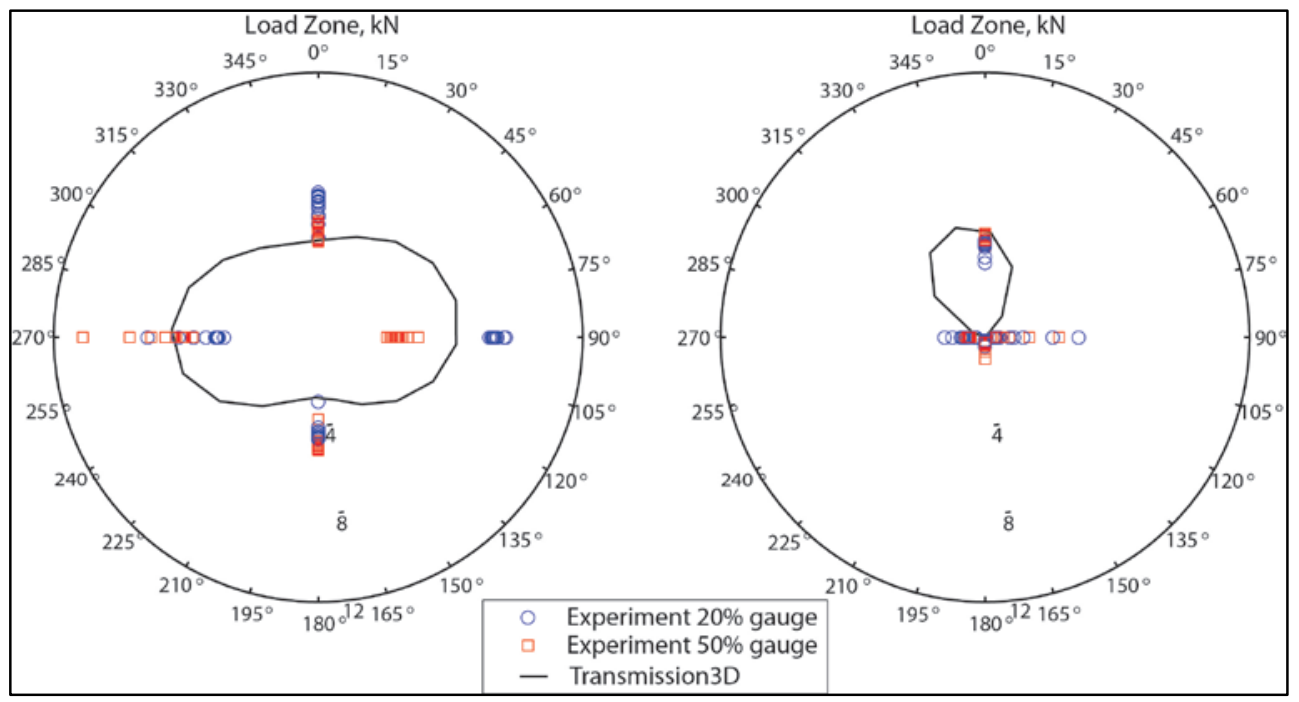

Figure 15. Downwind (left) and upwind (right) TRB load zones at $100 \%$ power 


\subsubsection{Measured Load Zone Shape Estimation}

The four circumferential measurement locations around each TRB provide only a coarse description of the load zones. These load-zone measurements can be directly compared to the Transmission3D model as discussed in the previous section; but, to calculate the total bearing forces for comparison to the SIMPACK and analytic models, the total load-zone area and loadzone center must be calculated. The four circumferential measurements are too coarse to be simply connected and integrated, as the resulting area results in an unacceptable amount of uncertainty. A more realistic overall shape of the load zone must be assumed for integration purposes.

Based on the Transmission3D model results shown in the previous section, an elliptical shape is assumed and used to integrate the direct measurements and calculate the total bearing loads in this section. The ellipse is curve-fitted to the average of the $20 \%$ and $50 \%$ measurements at each circumferential location. Elliptical fitting with these measurements proved to be challenging. Examples of this fitting process are shown in Figure 16 and Figure 17. As shown in Figure 16, the ellipses fitted to the average measured loads have similar shapes and amplitudes as the earlier Transmission3D load-zone predictions. Moreover, the principal axis of the upwind TRB ellipse nearly aligns with the direction of the HSS pinion mesh force shown in Figure 5.

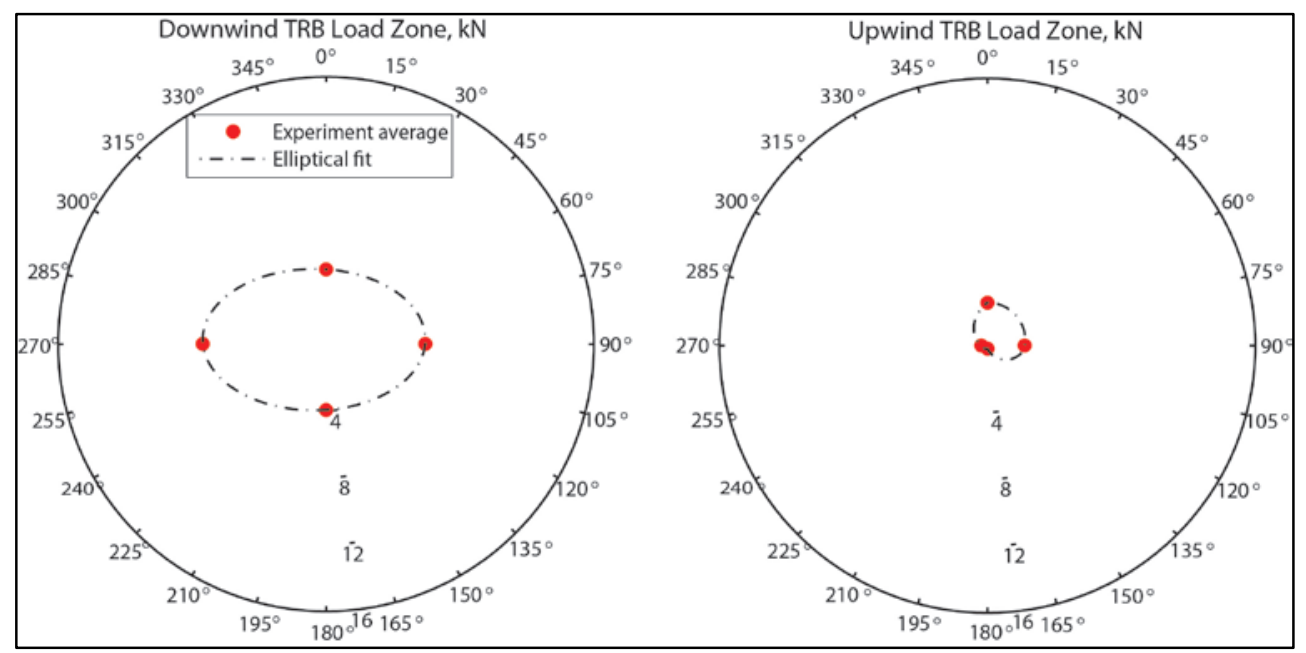

Figure 16. Realistic downwind (left) and upwind (right) TRB load-zone estimates

And yet, the ellipses fitted to the average measured loads shown in Figure 17 exhibit entirely different orientations and sizes than the Transmission3D model. These unrealistic ellipses result from an insufficient number of data points around the circumference. Additional measurements at $45^{\circ}, 135^{\circ}, 225^{\circ}$, and $315^{\circ}$ would have increased the accuracy of the ellipse-fitting process. The ellipse-fitting process thus adds an additional component of uncertainty in calculating the total bearing load, which varies with the quality of the fit. 


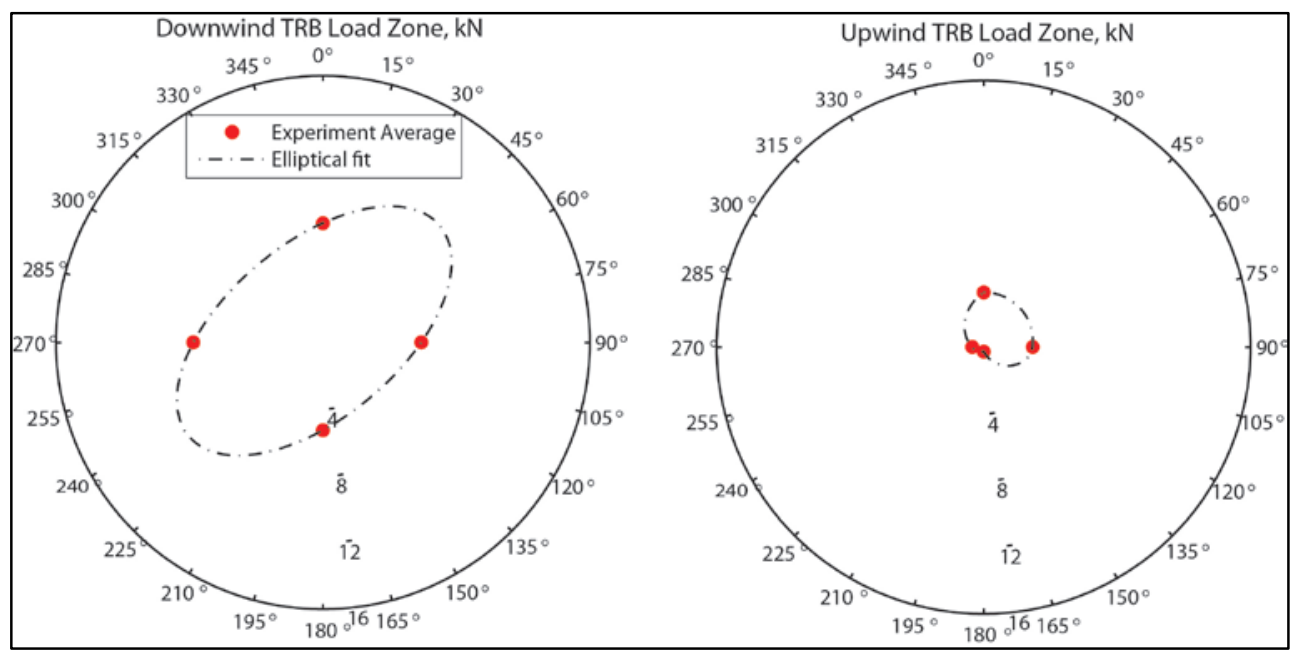

Figure 17. Unrealistic downwind (left) and upwind (right) TRB load-zone estimates

After the load-zone ellipse has been fitted to the average measured load, the total vertical, lateral, and axial loads can be calculated. The vertical and lateral loads are then combined into a total radial-load magnitude for comparison to the models. The magnitude of the axial and radial loads acting on the bearings is of the most interest.

\subsection{Bearing Radial and Axial Loads}

In this section, a process for time averaging the experimental data into the total TRB radial and axial loads is described. The resulting directly measured TRB axial and radial loads will be examined and compared to the four different models described earlier: the two variants of the analytic models, the SIMPACK model, and the Transmission3D model. The CRB radial load calculated from the analytic models will also be compared to the SIMPACK and Transmission3D models.

In each case, the bearing-load variation over the HSS revolution is examined because the measured HSS torque contains a $\pm 10 \%$ variation as shown in Figure 7 . Therefore, the bearing load from the analytic models will also contain a natural variation. However, the SIMPACK and Transmission3D models, in this work, are steady-state models and will not display such a characteristic.

\subsubsection{Bearing-Load Time Averaging}

As shown in previous sections, there are actually three sources of uncertainty in processing the measured bearing strain into total bearing loads: the time variation in the measured torque, the time variation in the load measurement at each circumferential location, and the load-zone ellipse fitting. The best means to reduce all of these uncertainties is time averaging.

A sensitivity study was thus performed to find the optimal time duration for time averaging of the bearing-load measurements into the total bearing loads. In steady-state conditions, the longer the time average, the lower the uncertainty in the total bearing load will be. However, measurement of the bearing loads in transient or other operational conditions prone to bearing sliding is of significant interest relative to the bearing white-etching area crack failure mode [5, 18]. Therefore, a shorter time average that yields the most consistent results is desired for this 
and future transient studies. The time-averaging sensitivity study was conducted as follows, considering only the $100 \%$ power condition. The bearing load at each axial and circumferential location was first calculated as shown in Figure 10, Figure 11, and Figure 12 (note that each point corresponds to a roller passing over the bearing outer race). The average load of the two axial measurements at each circumferential location was calculated and the load-zone ellipse was then fitted similar to Figure 16, but at each roller passage over the bearing outer race. From the load-zone ellipse, the total TRB radial loads were calculated, again for each roller passage. Thus, in each 1-second data acquisition, the loads were calculated at the outer-race roller passage frequency of $255 \mathrm{~Hz}$, or 255 times for each acquisition. The resulting time histories of the TRB radial loads are shown in Figure 18. The average loads for the downwind and upwind TRBs are $16.7 \mathrm{kN}$ and $23.8 \mathrm{kN}$, respectively. The downwind radial load contains more variability than the upwind load. This is primarily related to the load-zone ellipse fitting error shown in Figure 17.
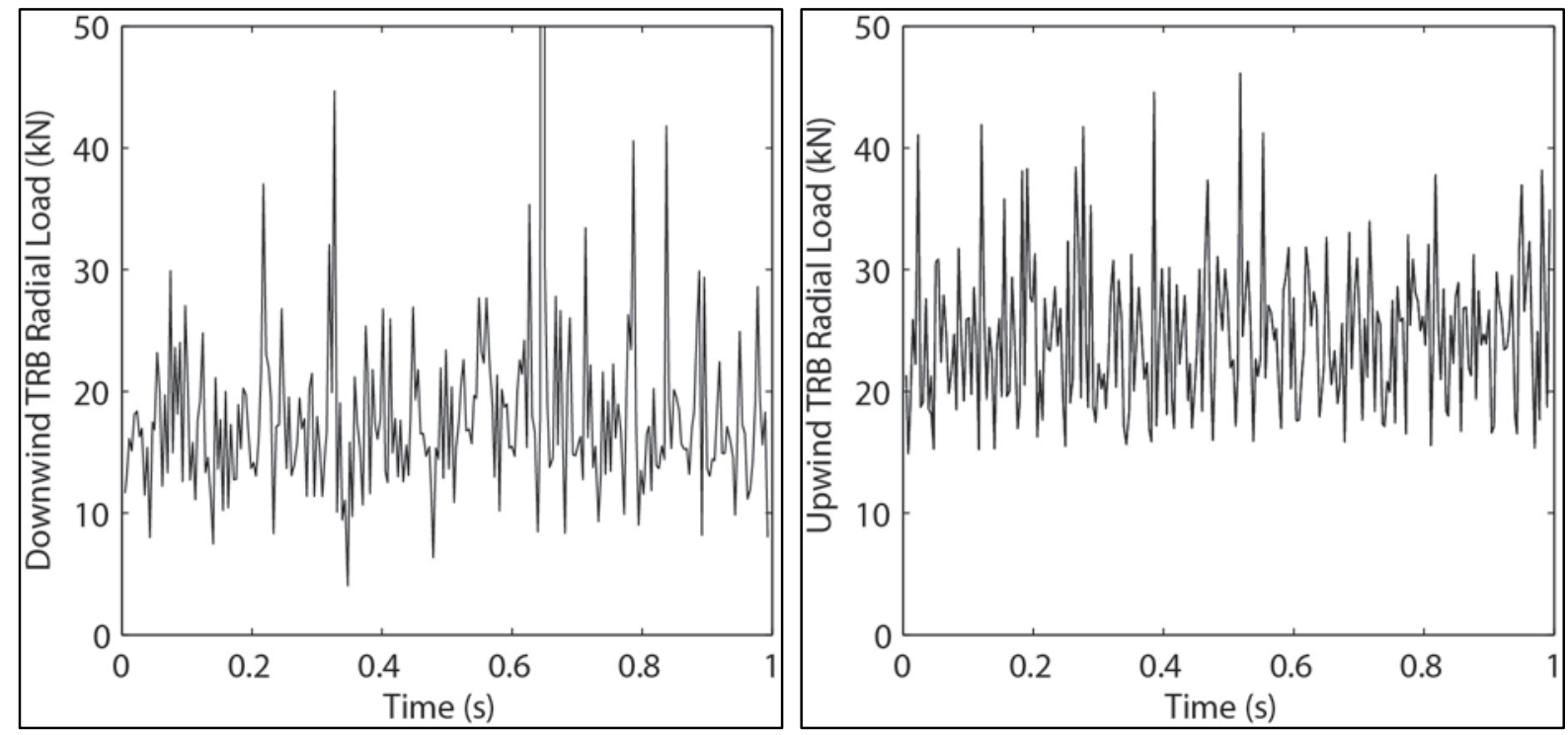

Figure 18. Processed downwind (left) and upwind (right) TRB radial loads

The processed radial-load data shown above were then parsed into multiple bins containing a specified number of roller passes in each bin. For each bin, the mean load was calculated. Then, the standard deviation of all the mean loads in the full 1-second data sample was calculated. This process was repeated for varying bin widths, from 2 to 80 roller passes. The standard deviations of the radial load for each TRB are shown in Figure 19. As described earlier, of interest is the shortest time-averaging period yielding the lowest reasonable standard deviation. As evident in the figures, the standard deviation rapidly decreases as the number of roller passes in each bin increases. For bin widths greater than 10 roller passes, the standard deviation does not decrease significantly. Therefore, 10 roller passes (equating to a 0.04 -second sample) were selected as the period of time averaging for all load processing in the following discussions. 

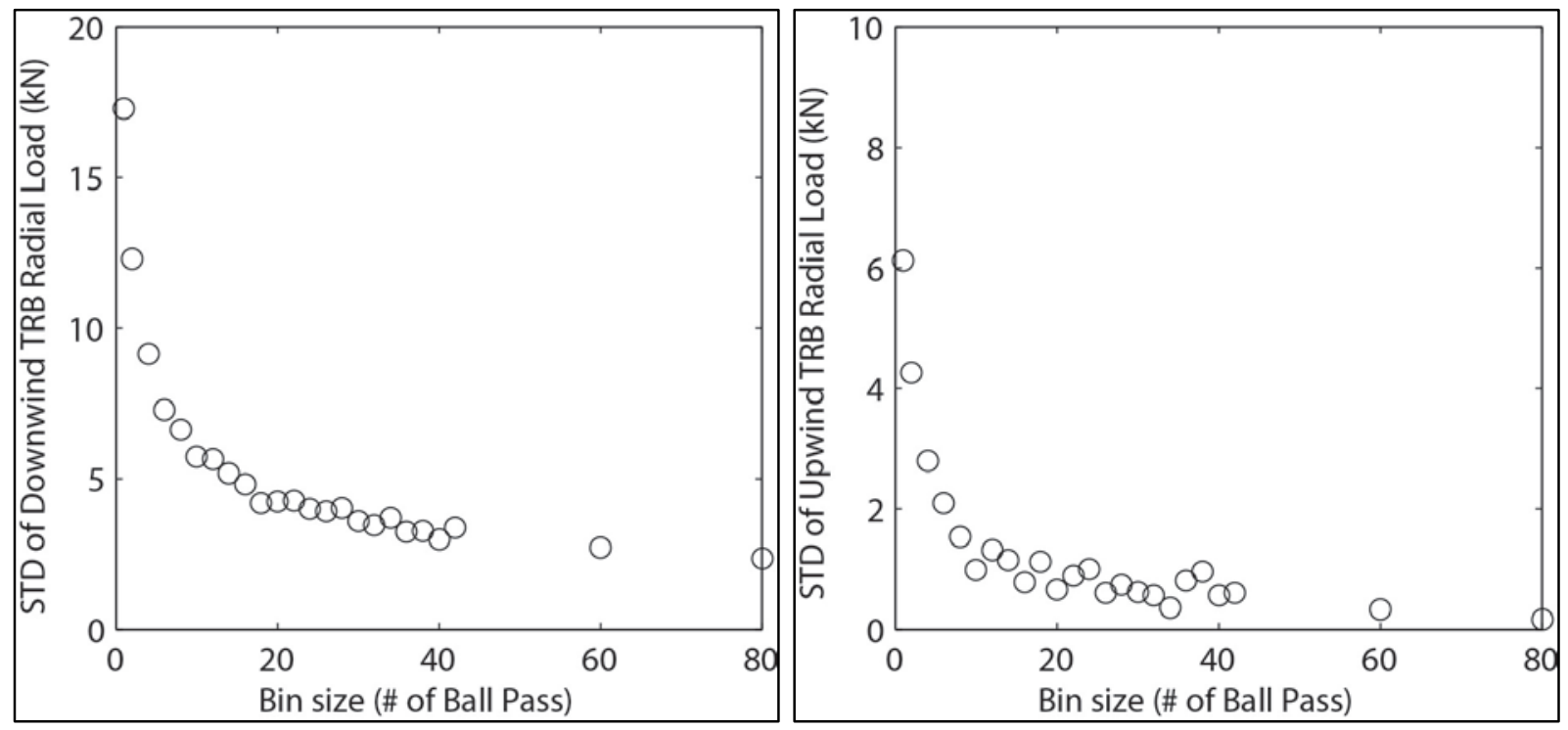

Figure 19. Standard deviation (STD) of downwind (left) and upwind (right) TRB radial loads

The resulting binned time histories of the TRB radial loads for the full power condition are shown in Figure 20. That is, Figure 20 is similar to Figure 18, but it has been fully time averaged to reduce the level of uncertainty in the radial-load measurements. Overlaid on the figures are grey bars equal to the mean load and \pm 1 standard deviation, representing the typical range of radial load. The average radial loads for the downwind and upwind TRBs are still $16.7 \mathrm{kN}$ and $23.8 \mathrm{kN}$, respectively, whereas the standard deviations are $5.7 \mathrm{kN}$ and $1.0 \mathrm{kN}$. Aside from one excursion in the binned data points for the downwind TRB caused by load-zone ellipse fitting, the binned data almost entirely falls within the grey area.
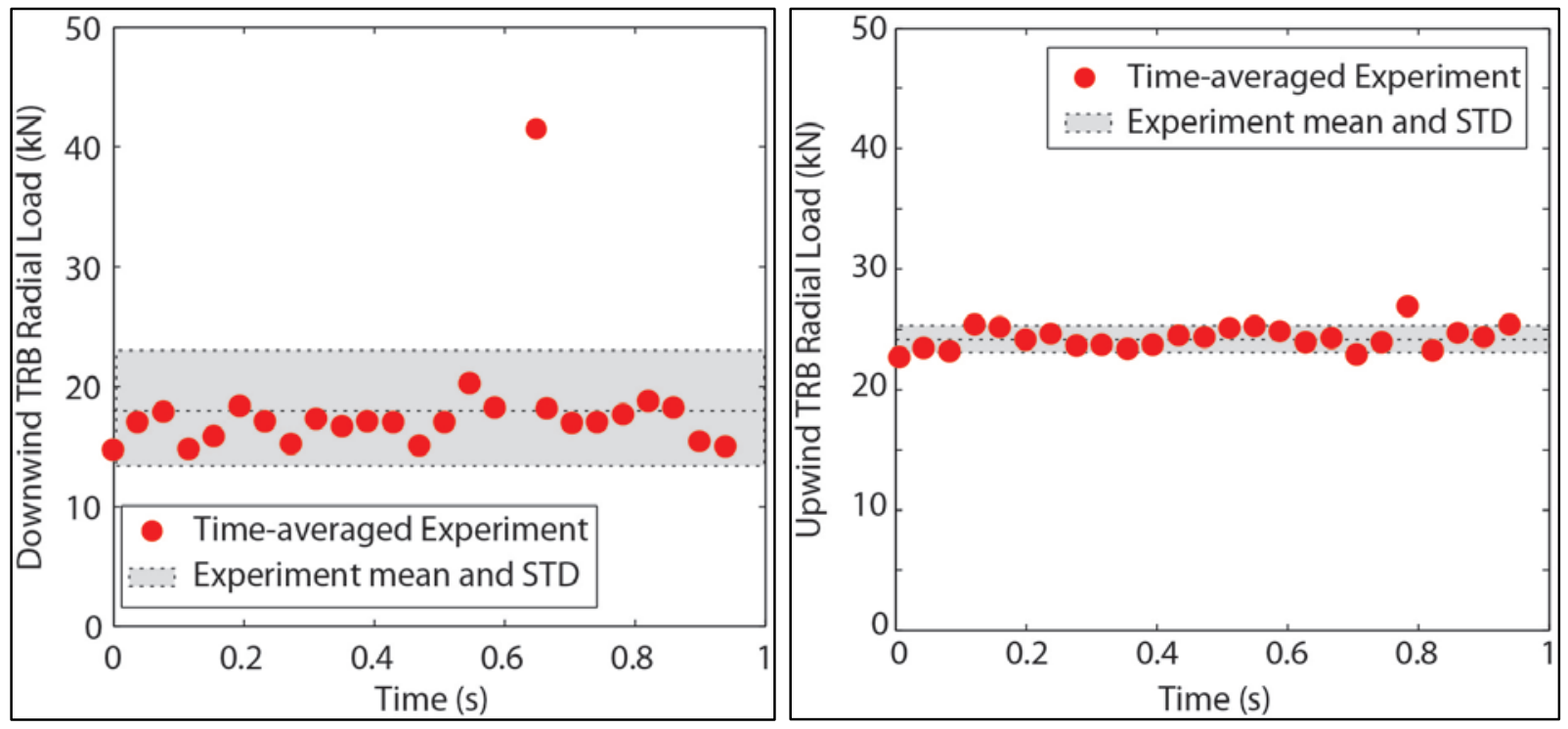

Figure 20. Time-averaged downwind (left) and upwind (right) TRB radial loads

Note that for a bin width of 10 roller passes, there are now only 25 processed radial-load points per 1 -second acquisition. The HSS rotates at $30 \mathrm{~Hz}$, or 30 times per second; therefore, there are 1.2 HSS revolutions per bin. Thus, it is not possible to associate a binned data point to a particular HSS azimuthal location. In the following figures, the grey bars, representing the 
typical load range, will be used to compare the measured bearing loads to the models over the HSS rotation rather than the individual binned data points in time.

\subsubsection{TRB Individual Radial Loads}

The assumption that the TRBs act as individual elements as described in section 3.1.2 yields the TRB individual radial loads shown in Figure 21 at 100\% power. Although the analytic model contains the once-per-revolution variation from torque, its average is comparable to the direct load measurement. However, for this case, the other models do not compare quite as well to the experimental measurements. The Transmission3D loads are lower than the measured results, while the SIMPACK results are higher for the downwind TRB load and significantly lower for the upwind TRB load.
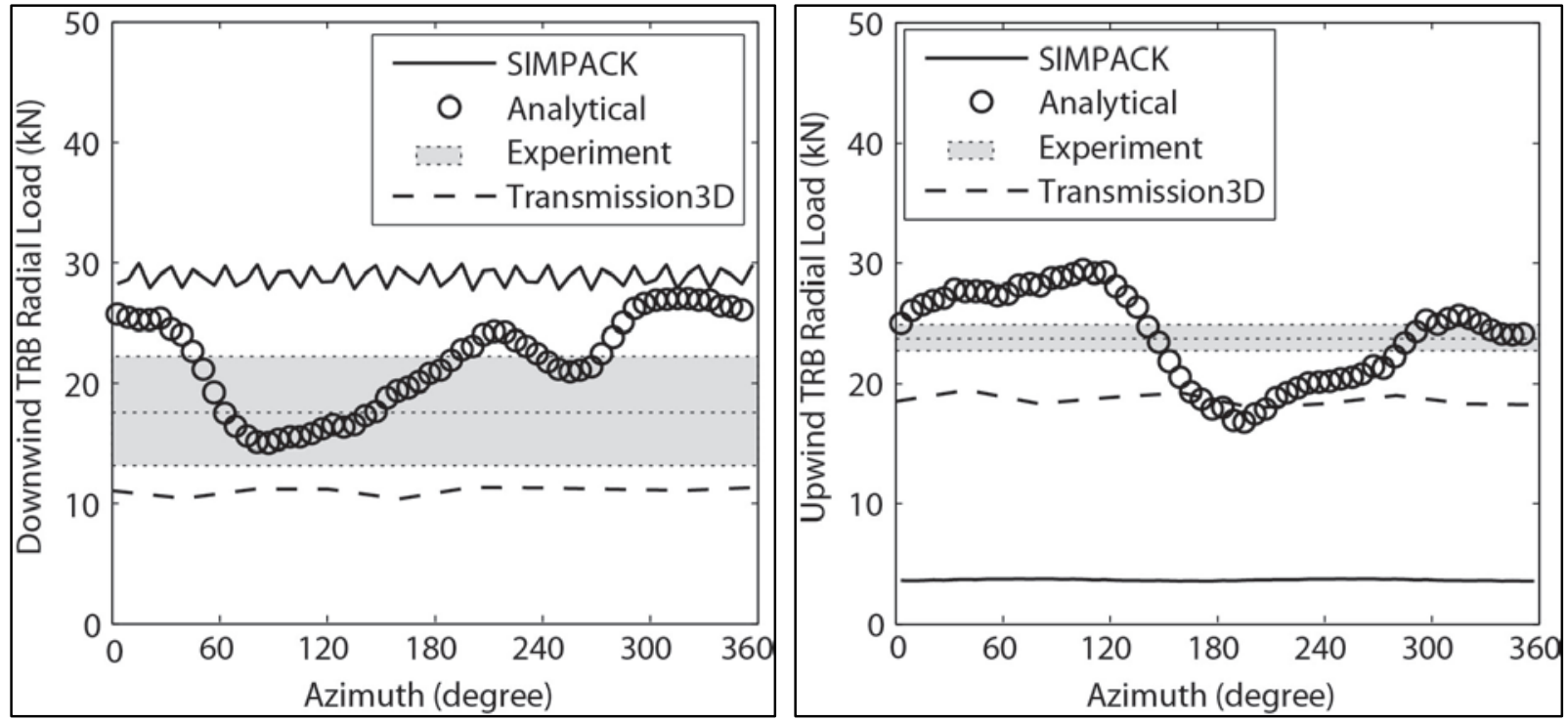

Figure 21. Comparison of downwind (left) and upwind (right) TRB radial loads

\subsubsection{TRB Pair Axial Load}

The total TRB axial load is shown in Figure 22 for only the full power condition. For the SIMPACK and Transmission3D models, the total axial load is the sum of the axial load for each TRB. For the experimental results, the axial load is calculated as a fraction of the radial load using the $16^{\circ}$ taper angle of the bearing [10]. Overall, the agreement is good between the experimental measurements and the models. The theoretical axial-mesh load is $18 \mathrm{kN}$, which is very close to the SIMPACK and Transmission3D results. However, the analytical and experimental measurements are slightly lower at approximately $13 \mathrm{kN}$. It is possible that friction in the system contributes some axial load, or that the generator coupling is actually supporting a small amount of axial load. 


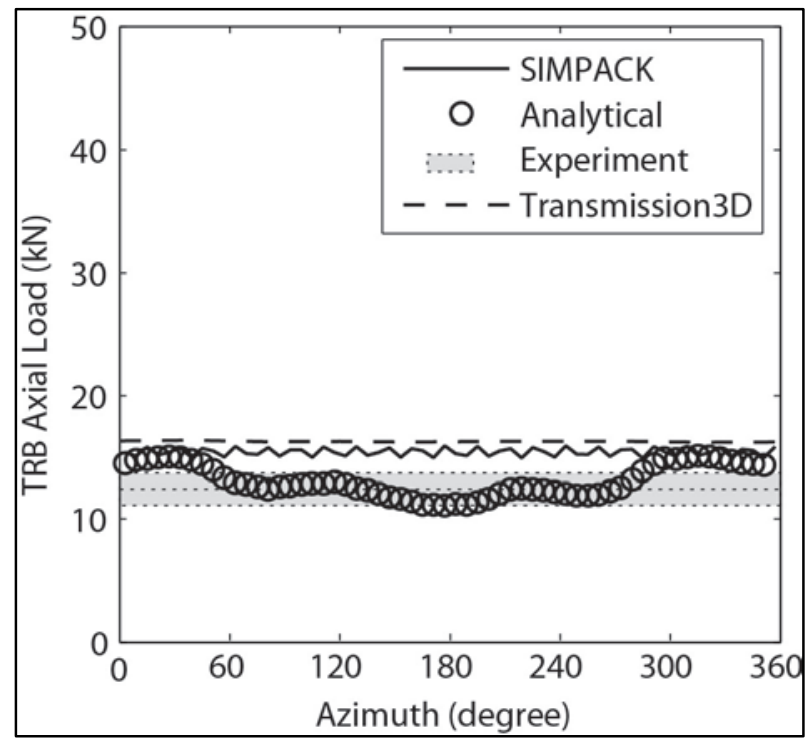

Figure 22. Comparison of TRB pair axial load

\subsubsection{TRB Pair Radial Load and Moment}

The assumption that the TRB pair acts as a single element as described in Section 1.1.13.1.1 yields the TRB radial load and moments shown in Figure 23. The TRB pair radial loads for each of the models are comparable to the experimental measurement. The TRB pair radial load is approximately $30 \mathrm{kN}$, which is nearly $40 \%$ of the theoretical radial-mesh load of $78 \mathrm{kN}$. The TRB pair moments, however, display an interesting disparity. The analytic model shows that the TRB pair carries a bending moment of $6 \mathrm{kNm}$. However, the SIMPACK and Transmission3D models estimate a much smaller moment of $0.5 \mathrm{kNm}$. This could be caused by the low installed preload of the TRBs. Without sufficient axial preload, the bearing raceways could misalign during operation and the rollers contact the raceway edges as indicated in Figure 15. The dislocated contact areas could cause the TRBs to react a larger bending moment than without raceway misalignment.
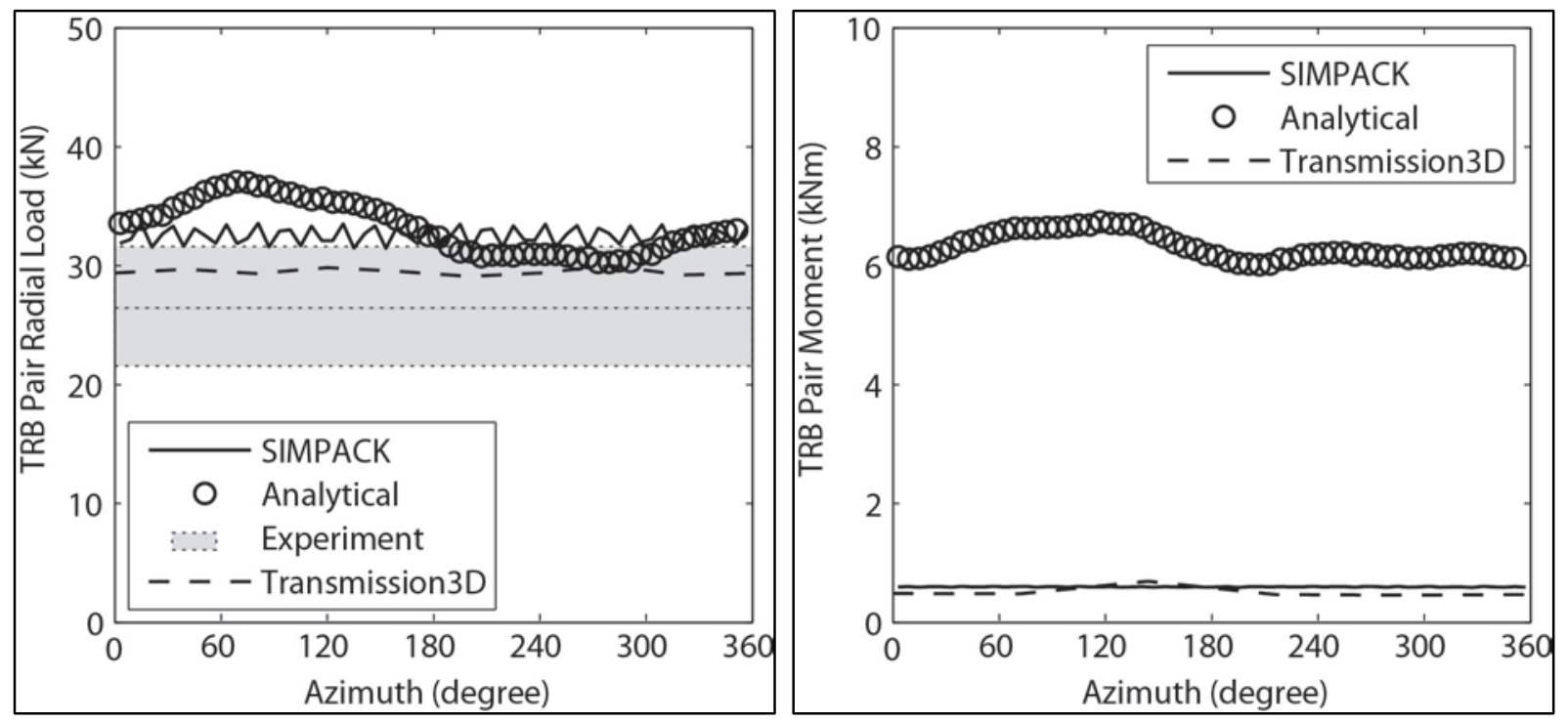

Figure 23. Comparison of TRB pair radial load (left) and moment (right) 


\subsubsection{CRB Radial Load}

Figure 24 shows the CRB radial load for the analytical, SIMPACK, and Transmission3D models. Although there is no direct measurement of the CRB radial load, comparison of the models can still provide some insight. The analytical model generally matches the SIMPACK and Transmission3D models. The CRB radial load at full power is approximately $45 \mathrm{kN}$, which is nearly $60 \%$ of the radial-mesh load of $78 \mathrm{kN}$. As the CRB is physically closer to the gear mesh than the TRB pair, the CRB carries the majority of the mesh load as expected.

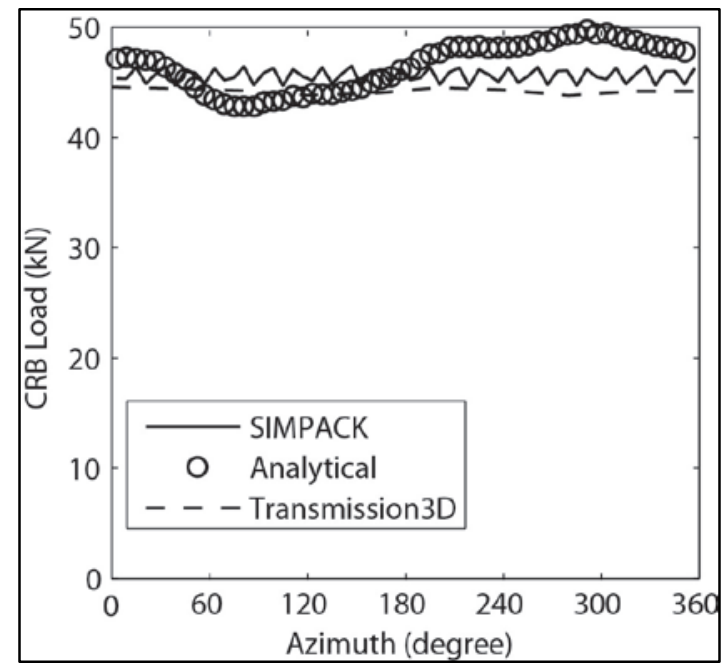

Figure 24. Comparison of CRB radial load

\subsubsection{Bearing Load Summary}

A summary of the CRB and TRB pair radial loads is shown in Figure 25. In this figure, only the average load for the entire acquisition is shown, rather than the variation in time or in the HSS azimuth. The bearing loads increase linearly with power, as expected, because the gear-mesh forces increase linearly with power. Across the range of power, the models compare favorably to the experimental measurements, with the exception of offline conditions. There, the loads are so low that uncertainty in the load-zone ellipse estimation is the dominating factor.

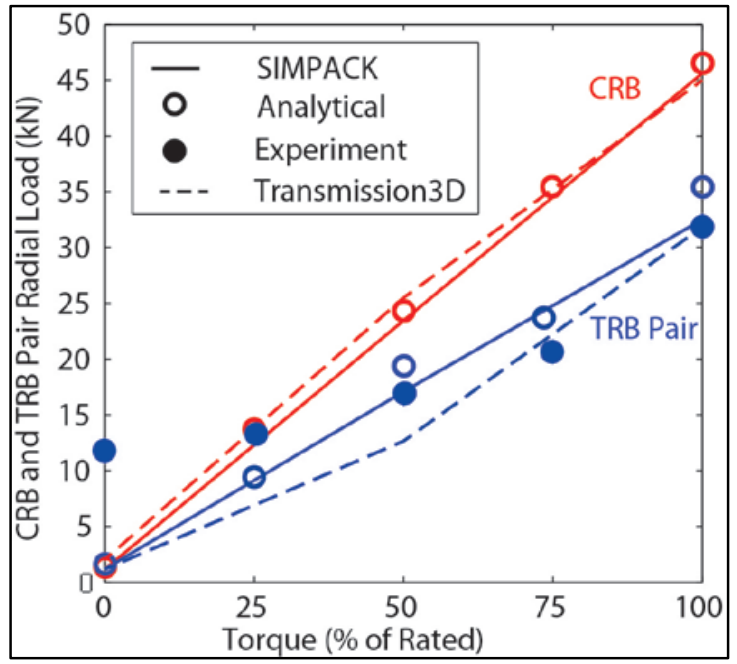

Figure 25. Variation of HSS bearing loads with torque 


\subsection{Bearing Stresses}

Understanding stresses in the bearing races is critical for the design and life prediction of gearboxes, for both rolling contact fatigue and bearing white-etching area cracks [5]. In this section, the HSS TRB inner and outer race surface contact pressures, subsurface shears, and subsurface von Mises stresses are investigated using the Tranmission3D model, which is the only tool considered in this study capable of predicting these stress fields. The stress fields were calculated in offline, $50 \%$, and $100 \%$ power conditions.

Figure 26 shows the bearing-race surface contact pressures for the downwind and upwind TRBs. The maximum surface contact pressures increase linearly with power, and the inner race stresses are equal to or greater than the outer race stresses. As expected from the load zones shown in Figure 13, Figure 14, and Figure 15, the downwind TRB has a much more constant load zone compared to the upwind TRB. Less than half of the upwind TRB races are loaded. The rollers in the upwind TRB are at a greater risk of sliding as they enter and exit the load zone at $60^{\circ}$ and $270^{\circ}$ than for the downwind TRB. Although the load zones are drastically different in size and shape, the maximum surface-contact pressures are similar for the bearings at full power. The maximum surface contact pressure of 900 megapascals (MPa) is less than the recommended limits for contact fatigue in the range of 1,300 to $1,500 \mathrm{MPa}[19,20]$ and for the development of white bands near 2,500 MPa [21].

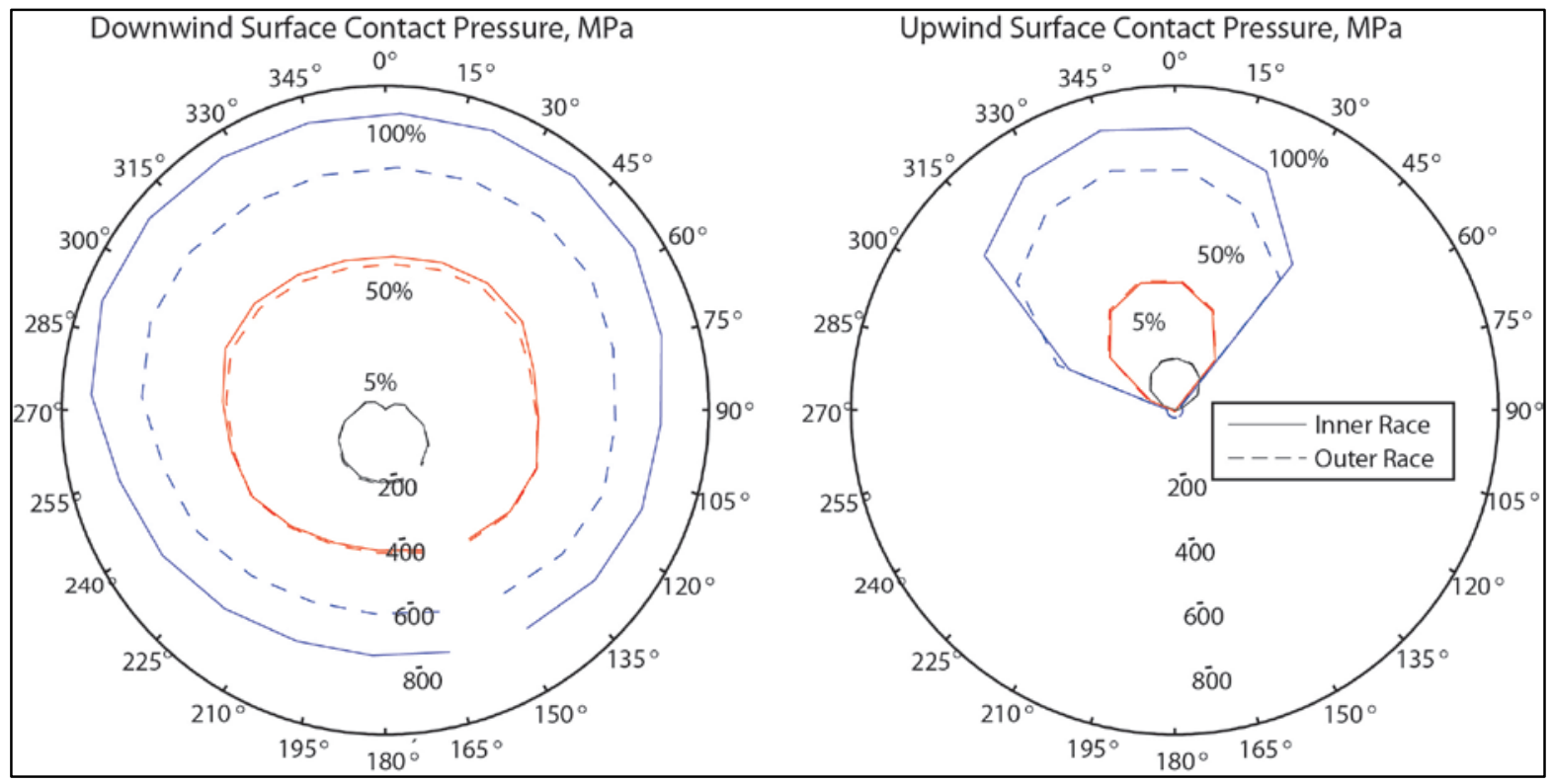

Figure 26. Downwind (left) and upwind (right) surface contact pressures

The maximum subsurface von Mises and shear stresses are shown in Figure 27 and Figure 28. Material yielding begins when the maximum von Mises stress is nearly half of the yielding strength. The subsurface stresses have similar shapes as the surface contact pressure, although the stresses are much lower. The maximum von Mises and shear stresses are $478 \mathrm{MPa}$ and 255 $\mathrm{MPa}$ for the downwind bearing and $463 \mathrm{MPa}$ and $248 \mathrm{MPa}$ for the upwind bearing. These maximum stresses were found about $30 \mu \mathrm{m}$ beneath the inner race surface, which equals $79 \%$ of the hertz semiwidth of the contact zone. These stress amplitudes were compared against several stress thresholds. The subsurface shear stress is less than the $400 \mathrm{MPa}$ limit for the development 
of butterflies [21]. The subsurface von Mises stress is also less than the fatigue limit of $684 \mathrm{MPa}$ for American National Standards Institute 52100 steel [22]. These comparisons indicate the TRBs are operating below the thresholds of these specific failure modes, at least when operating in steady-state conditions.

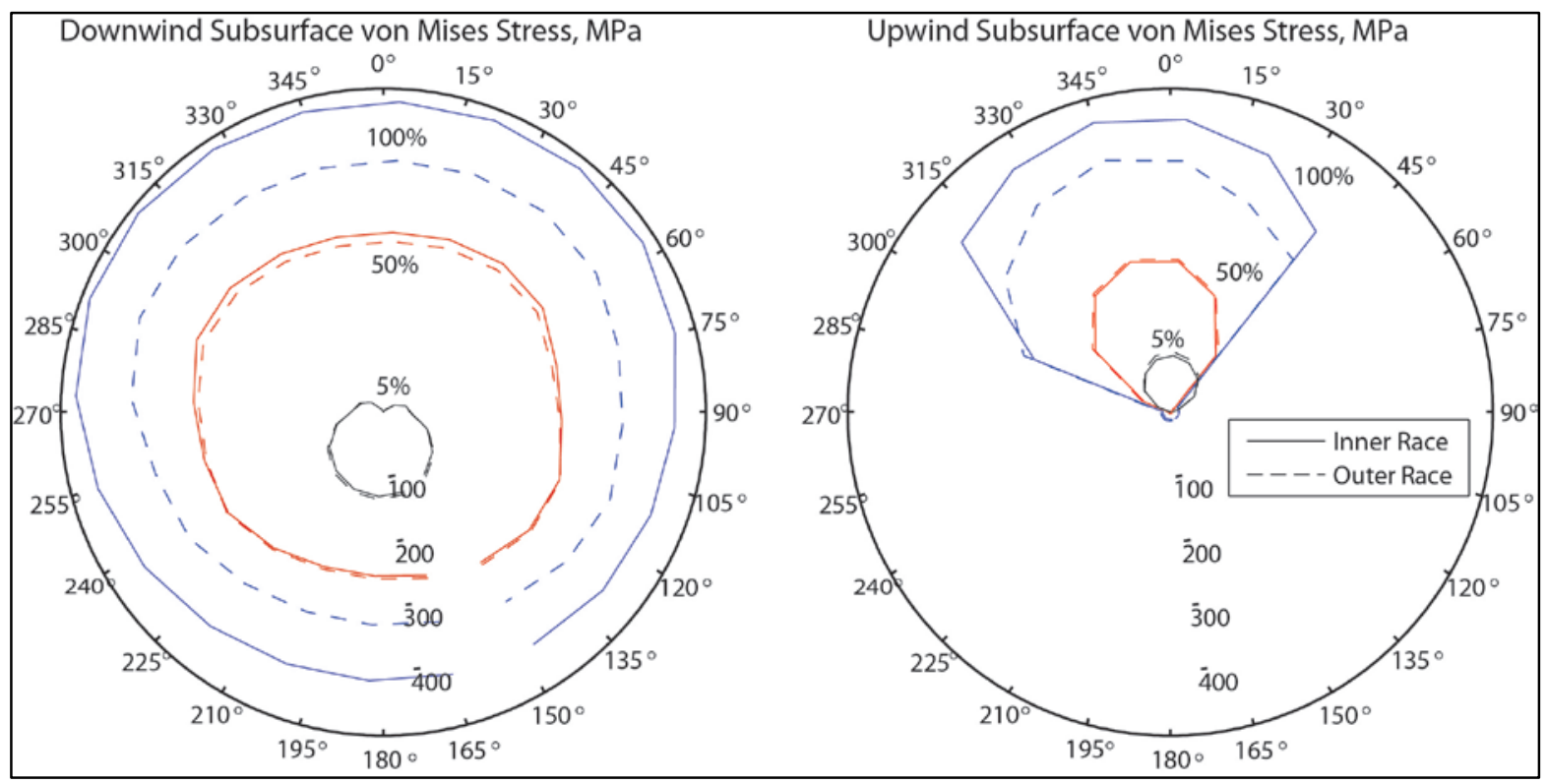

Figure 27. Downwind (left) and upwind (right) maximum subsurface von Mises stresses

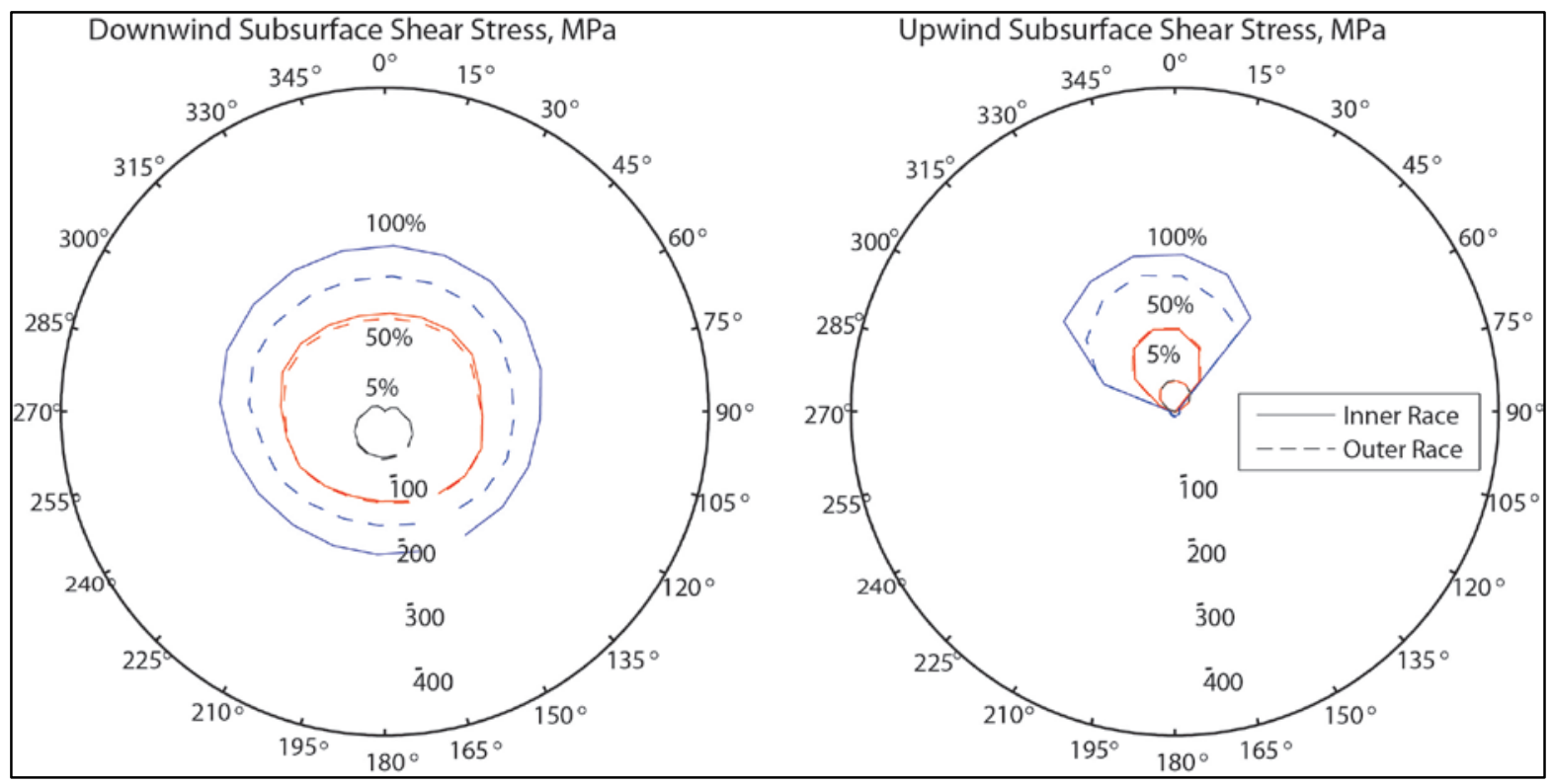

Figure 28. Downwind (left) and upwind (right) maximum subsurface shear stresses 


\section{Conclusions}

Motivated by the prevalence of failures in HSS bearings of wind turbine gearboxes, the loads and stresses were examined in the HSS bearings of the GRC gearbox in this work. The HSS TRB bearing loads were measured during dynamometer tests for comparison to analytical and highfidelity SIMPACK and Transmission3D models of the GRC gearbox. In general, there was good agreement between the models and the experimental measurements across the full range of gearbox power and torque levels tested. Major observations from this validation exercise are summarized below:

- Bearing load zones. The direct measurement of the TRB loads at four circumferential and two axial locations around the bearing outer raceway correlated to the Transmission3D full-finite element model. However, with only four circumferential measurements, subsequent estimation of the measured load-zone shape was difficult. An additional two to four measurement locations would have improved the load-zone shape estimation.

- Bearing radial loads. The difficulties in load-zone shape estimation led to a higher than desired amount of uncertainty in estimation of the measured bearing radial load. Timeaveraging of the bearing radial loads over 10 roller passes $(0.04 \mathrm{~s})$ was used to reduce the amount of uncertainty in the near steady-state conditions tested. But, in very rapidly changing transient conditions, this would limit the comparability of direct measurements to models.

- Analytical model development. A simple analytic model was developed to efficiently calculate bearing radial and axial loads based on measured HSS bending and torque. Two versions were developed — one modeled the TRB pair as a single element and the other modeled the TRBs as individual elements. The radial and axial loads predicted by each approach were very comparable to the experimental data, although the torque variation has a strong influence on the analytical model results. Neither analytic model predicts bearing stresses nor the bearing load zone.

- High-fidelity models. Multibody and finite element/contact mechanics models served different purposes in this study, although both compute bearing loads. The multibody model produces a relatively fast solution for bearing loads but it does not present any information on the bearing load zones or stresses. The finite element/contact mechanics model requires significant computation time but it provides insight into the bearing load zone and stress fields at the contact surface and the subsurface.

For the GRC gearbox, in future work additional test cases, including generator misalignment and dynamic events such as grid disconnect and braking and their effect on bearing loads, will be examined. In the next phase of the GRC program, the HSS bearings of a commercial gearbox will be instrumented and tested in a field turbine to explore the loads, speeds, and other tribological factors in operation in relation to the bearing axial cracking failure mode [18]. 


\section{References}

1. Sheng, Shawn. "Wind Turbine Condition Monitoring, Reliability Database, and O\&M Research Update" (presented at the GRC Annual Meeting 2015, Golden, CO, February 1718, 2015). PR-5000-63868, National Renewable Energy Laboratory (NREL), Golden, CO (US), 2015.

2. Kotzalas, Michael N., and Gary L. Doll. "Tribological advancements for reliable wind turbine performance." Philosophical Transactions of the Royal Society A 2010368 (2010): 4829-4850. http://dx.doi.org/10.1098/rsta.2010.0194.

3. Errichello, R., S. Sheng, J. Keller, and A. Greco. 2012. Wind Turbine Tribology Seminar-A Recap. (Technical Report). NREL/TP-5000-53754. National Renewable Energy Laboratory (NREL), Golden, CO (US). DOE/GO-102012-3496. http://www.nrel.gov/docs/fy12osti/53754.pdf.

4. Greco, A., S. Sheng, J. Keller, and A. Erdemir. "Material wear and fatigue in wind turbine Systems." Wear. Vol. 302(1-2), April-May 2013; pp. 1583-1591. http://dx.doi.org/10.1016/j.wear.2013.01.060.

5. Gould, Benjamin, and Aaron Greco. "The Influence of Sliding and Contact Severity on the Generation of White Etching Cracks.” Tribology Letters (2015) 60:29, DOI 10.1007/s11249015-0602-6.

6. Stadler, Kenred, and Arno Stubenrauch. "Premature Bearing Failures in Wind Gearboxes and White Etching Cracks." Power Transmission Engineering, October 2014. Accessed December 10, 2015. http://www.powertransmission.com/issues/1014/Premature_Bearing_Failures_PTE1014.pdf.

7. Link, H., W. LaCava, J. van Dam, B. McNiff, S. Sheng, R. Wallen, M. McDade, S. Lambert, S. Butterfield, and F. Oyague. 2011. Gearbox Reliability Collaborative Project Report: Findings from Phase 1 and Phase 2 Testing. (Technical Report). NREL/TP-5000-51885. National Renewable Energy Laboratory (NREL), Golden, CO (US). http://www.nrel.gov/docs/fy11osti/51885.pdf.

8. Link, H., J. Keller, Y. Guo, and B. McNiff. 2013. Gearbox Reliability Collaborative Phase 3 Gearbox 2 Test Plan. (Technical Report). NREL/TP-5000-58190. National Renewable Energy Laboratory (NREL), Golden, CO (US). http://www.nrel.gov/docs/fy13osti/58190.pdf.

9. Keller, J., and B. McNiff. 2014. Gearbox Reliability Collaborative High-Speed Shaft Calibration. (Technical Report). NREL/TP-5000-62373. National Renewable Energy Laboratory (NREL), Golden, CO (US). http://www.nrel.gov/docs/fy14osti/62373.pdf.

10. Keller, J., Y. Guo, and B. McNiff. 2013. Gearbox Reliability Collaborative High Speed Shaft Tapered Roller Bearing Calibration. (Technical Report). NREL/TP-5000-60319. National Renewable Energy Laboratory (NREL), Golden, CO (US). http://www.nrel.gov/docs/fy14osti/60319.pdf. 
11. Keller, J., and R. Wallen. 2015. Gearbox Reliability Collaborative Phase 3 Gearbox 2 Test Report. (Technical Report). NREL/TP-5000-63693. National Renewable Energy Laboratory (NREL), Golden, CO (US). http://www.nrel.gov/docs/fy15osti/63693.pdf.

12. McNiff, B., Y. Guo, J. Keller, and L. Sethuraman. 2014. "High-Speed Shaft Bearing Loads Testing and Modeling in the NREL Gearbox Reliability Collaborative" (presented at the Conference for Wind Power Drives, Aachen, Delaware, March 3-4, 2015). NREL/CP-500063277. National Renewable Energy Laboratory (NREL), Golden, CO (US). http://www.nrel.gov/docs/fy15osti/63277.pdf.

13. Keller, J., Y. Guo, and L. Sethuraman. 2016. Gearbox Reliability Collaborative Investigation of Generator Motion and High-Speed-Shaft Loads. (Technical Report). NREL/TP-500065321. National Renewable Energy Laboratory (NREL), Golden, CO (US). http://www.nrel.gov/docs/fy16osti/65321.pdf.

14. Errichello, R., and J. Muller. 2012. Gearbox Reliability Collaborative Gearbox 1 Failure Analysis Report: December 2010-January 2011. (Technical Report). NREL/SR-5000-53062. National Renewable Energy Laboratory (NREL), Golden, CO (US). http://www.nrel.gov/docs/fy12osti/53062.pdf.

15. Houser, D.R. "Causes of GRC High Speed Shaft Dynamic Torque Variations" (presented at the GRC Annual Meeting 2015, Golden, CO, February 17-18, 2015).

16. Vijayakar, S. "A combined surface integral and finite element solution for a threedimensional contact problem." International Journal for Numerical Methods in Engineering Vol. 31 (3), March 5,1991; pp. 525-545. doi:10.1002/nme.1620310308.

17. Austin, J., D. Talbot, D. Houser, and S. Vijayakar. “A Finite Element Evaluation of a Bearing Instrumentation Method for Evaluating Bearing Load Distributions and Roller Stresses of the Final Drive of a Wind Turbine Gearbox" (presented at the International Gear Conference, Lyon-Villeurbanne, France, August 26-28, 2014).

18. Keller, J., D. Vaes, and B. McNiff. "The 'GRC1.5': Uptower Gearbox Testing to Investigate Bearing Axial Cracking” (presented at the Drivetrain Reliability Workshop, Golden, CO, February 16, 2016). NREL/PR-5000-65738. National Renewable Energy Laboratory (NREL), Golden, CO (US). http://www.nrel.gov/docs/fy16osti/65738.pdf.

19. ANSI/AGMA/AWEA 6006-A03, Design and Specifications of Gearboxes for Wind Turbines, 2011.

20. ISO 281:2007, Rolling bearings—-Dynamic load ratings and rating life.

21. Errichello, R., "Microstructural Alterations in Hertzian Fatigue." http://www.nrel.gov/wind/pdfs/day2_sessioniii_3a_geartech_errichello.pdf. Accessed March $16,2016$.

22. Harris, T.A., and M. N. Kotzalas. "Rolling Element Analysis: Advanced Concepts of Bearing Technology," 5th edition. Taylor \& Francis, 2007. 